\title{
Strain engineering and bioprocessing strategies for biobased production of porphobilinogen in Escherichia coli
}

Davinder Lall, Dragan Miscevic, Mark Bruder, Adam Westbrook, Marc Aucoin, Murray Moo-Young and

C. Perry Chou* (1)

\begin{abstract}
Strain engineering and bioprocessing strategies were applied for biobased production of porphobilinogen (PBG) using Escherichia coli as the cell factory. The non-native Shemin/C4 pathway was first implemented by heterologous expression of hemA from Rhodopseudomonas spheroids to supply carbon flux from the natural tricarboxylic acid (TCA) pathways for PBG biosynthesis via succinyl-CoA. Metabolic strategies were then applied for carbon flux direction from the TCA pathways to the C4 pathway. To promote PBG stability and accumulation, Clustered Regularly Interspersed Short Palindromic Repeats interference (CRISPRi) was applied to repress hemC expression and, therefore, reduce carbon flowthrough toward porphyrin biosynthesis with minimal impact to cell physiology. To further enhance PBG biosynthesis and accumulation under the hemC-repressed genetic background, we further heterologously expressed native E. coli hemB. Using these engineered E. coli strains for bioreactor cultivation based on $30 \mathrm{~g} \mathrm{~L}^{-1}$ glycerol, we achieved high PBG titers up to $209 \mathrm{mg} \mathrm{L}^{-1}$, representing $1.73 \%$ of the theoretical PBG yield, with improved PBG stability and accumulation. Potential biochemical, genetic, and metabolic factors limiting PBG production were systematically identified for characterization.
\end{abstract}

Keywords: Escherichia coli, Glycerol, Glyoxylate shunt, Porphobilinogen (PBG), Strain engineering, Succinyl-CoA, Tricarboxylic acid (TCA) cycle

*Correspondence: cpchou@uwaterloo.ca

Department of Chemical Engineering, University of Waterloo, 200

University Avenue West, Waterloo, ON N2L 3G1, Canada 


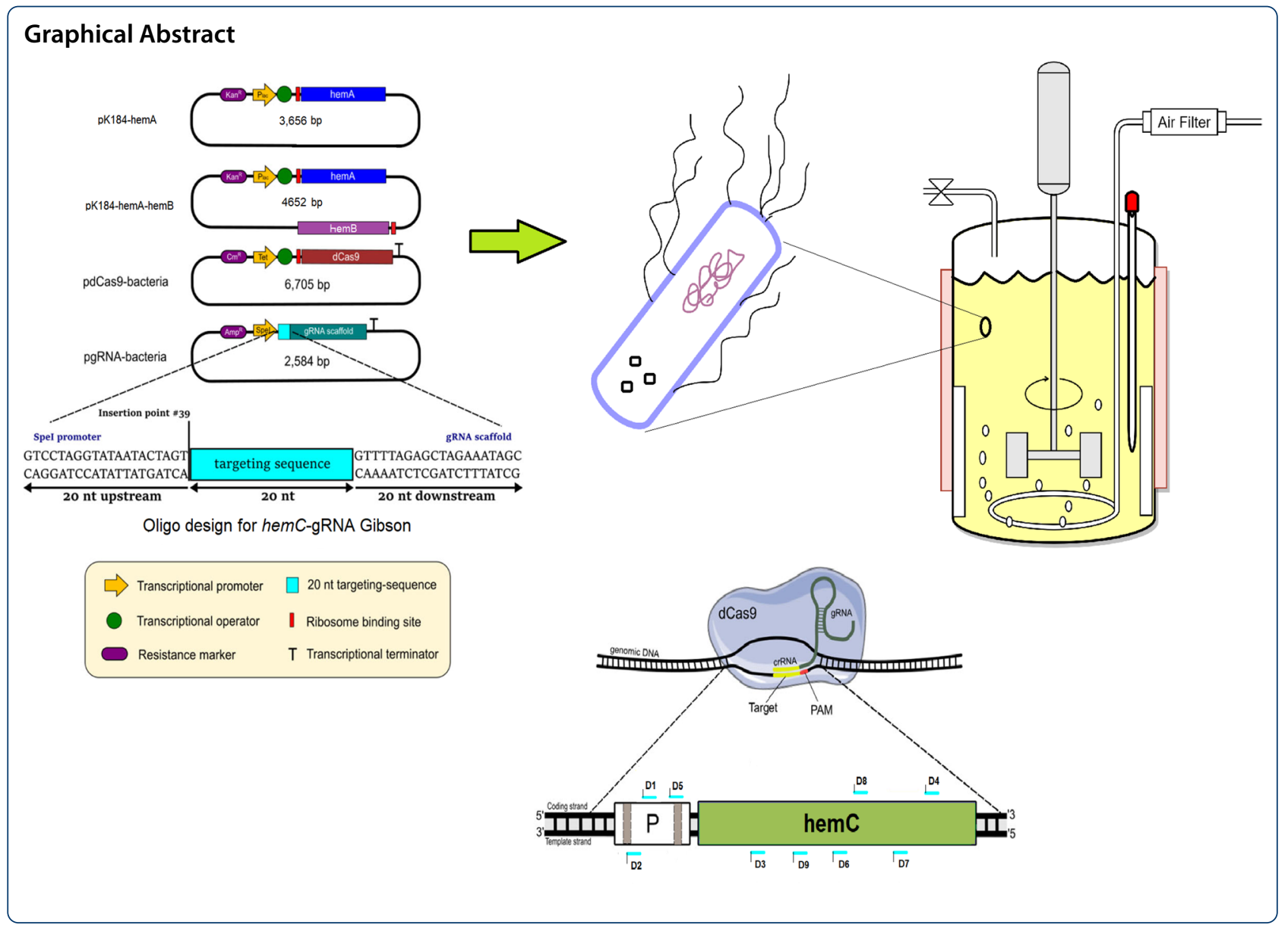

\section{Introduction}

Porphobilinogen (PBG) is a pyrrole-containing intermediate in the metabolic pathways for biosynthesis of essential porphyrin/tetrapyrrole compounds known as "pigments of life", including heme, cobalamin, chlorophyll, siroheme, heme $d_{1}$, etc., in almost all types of biological cells (Frankenberg et al. 2003). For application purposes, PBG can act as a marker for diagnosis of diseases, such as acute intermittent porphyria (Anderson 2019) and lead (Pb) poisoning (Gibson et al. 1968). Naturally in biological systems, the precursor of PBG, i.e., 5-aminolevulinic acid (5-ALA), is synthesized via either of the two unrelated metabolic routes, i.e., the Beale/ C5 pathway and the Shemin/C4 pathway (Zhang et al. 2015). Found in most bacteria (including Escherichia coli) and all archaea and plants, the C5 pathway starts with the C5-skeleton of glutamate for conducting two enzymic reactions, i.e., initial reduction of glutamyl-tRNA to glutamate-1-semialdehyde (GSA) via NADPH-dependent glutamyl-tRNA reductase (GluTR) and subsequent transamination of GSA via glutamate-1-semialdehyde2,1-aminomutase (GSAM), to form 5-ALA (Jahn et al.
1992). On other hand, the C4 pathway, present in humans, animals, fungi and the $\alpha$-group of proteobacteria, involves ALA synthase (ALAS or HemA, encoded by hemA) for molecular condensation of succinyl-CoA and glycine to form 5-ALA with the release of carbon dioxide and coenzyme A (CoA) (Nandi 1978). Subsequently, PBG is synthesized via a common reaction for molecular condensation of two 5-ALA molecules catalyzed by ALA dehydratase (ALAD or HemB, encoded by hemB) (Layer et al. 2010).

Even with relatively limited applicability up to date, technologies for PBG production have been explored. Chemical synthesis of PBG has been carried out using a variety of precursor molecules, such as diethyl 4-oxopimelate (Jones et al. 1976), 2-methoxy-4-methyl5-nitropyridine (Frydman et al. 1965), and 2-Hydroxy4-methyl-5-nitropyridine (Frydman et al. 1969), as well as reaction processes, such as modified synthesis via a porphobilinogen lactam (Kenner et al. 1977), MacDonald's method (Jackson and MacDonald 1957), and ozonide cleavage reaction (Jacobi and Li 2001). However, these chemical approaches are expensive, 
time-consuming, complex, and requiring harsh reaction conditions with typically low yields (Neier 2000). While purification of PBG from the urine of patients with acute porphyria is feasible, the producing capacity is knowingly limited (Westall 1952). While biosynthesis of PBG has been alternatively explored in different microbial cell factories, such as Rhodopseudomonas spheroides (Hatch and Lascelles 1972b), E. coli (Lee et al. 2013), Chromatium vinosum (Vogelmann et al. 1975), Propionibacterium freudenreichii, etc. (Piao et al. 2004), enhancing such biobased production is considered technically challenging since PBG, as a metabolic intermediate, hardly accumulates.
While various cell factories have been developed for biobased production (Chen et al. 2013), bacterium E. coli remains the most common one. In native E. coli, PBG is synthesized via the $\mathrm{C} 5$ pathway and barely accumulates extracellularly since the produced PBG will be readily tetramerized into hydroxymethylbilane $(\mathrm{HMB})$ via porphobilinogen deaminase (PBGD or HemC, encoded by $h e m C$ ) for subsequent biosynthesis of essential porphyrins, such as heme. In this study, we chose to first implement the non-native $\mathrm{C} 4$ pathway into $E$. coli for PBG biosynthesis and promote PBG extracellular accumulation, from the structurally unrelated carbon of glycerol by heterologous expression of hemA from $R$. spheroids (Fig. 1). Recently, glycerol has been recognized as a

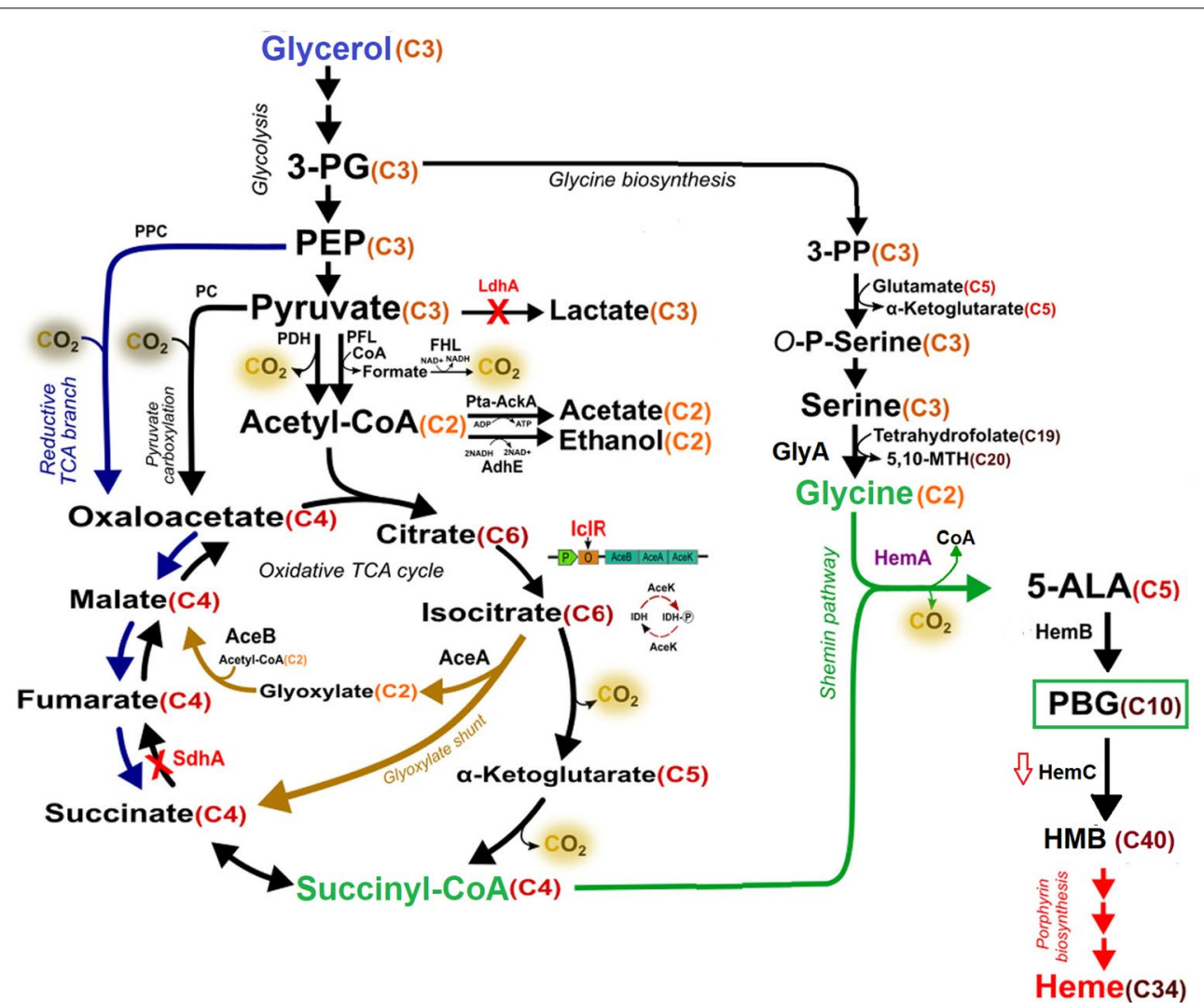

Fig. 1 Schematic representation of the natural metabolism and the implemented Shemin pathway for PBG and porphyrin biosynthesis in $E$. coli from glycerol. Metabolic pathways outlined: glycolysis, glycine biosynthesis, pyruvate carboxylation, and oxidative TCA cycle (in black); glyoxylate shunt in the TCA cycle (in light brown); reductive branch of TCA cycle (in blue); Shemin/C4 pathway and its key precursors (in green); porphyrin formation (in red). Colored proteins: mutations (in red); heterologous expression (in purple); carbon source: glycerol (in blue). Metabolite abbreviations: 5, 10-MTH 5,10-methenyltetrahydrofolic acid, 5-ALA 5-aminolevulinic acid, 3-PG 3-phosphoglycerate, 3-PP 3-phosphooxypyruvate, O-P-Serine O-phospho-L-serine, PBG porphobilinogen; HMB hydroxymethylbilane, PEP phosphoenolpyruvate, CoA coenzyme A. The number of carbon atoms for each metabolite is specified in orange/red. Protein abbreviations: AceA isocitrate lyase, AceB malate synthase $A$, AceK isocitrate dehydrogenase kinase/phosphatase, AckA acetate kinase, AdhE aldehyde-alcohol dehydrogenase, FHL formate hydrogenlyase, HemA 5-aminolevulinate synthase, HemB 5-aminolevulinate dehydratase, HemC porphobilinogen deaminase, ICIR AceBAK operon repressor, IDH isocitrate dehydrogenase, IDH-P isocitrate dehydrogenase-phosphate, $L d h A$ lactate dehydrogenase A, $P C$ pyruvate carboxylase, $P C k A$ phosphoenolpyruvate carboxykinase, $P D H$ pyruvate dehydrogenase, PFL pyruvate formate-lyase, $P K$ pyruvate kinase, $P P C$ phosphoenolpyruvate carboxylase, $P$ ta phosphotransacetylase, SdhA succinate dehydrogenase complex (subunit A) 
promising carbon source for biobased production due to its low cost (Ciriminna et al. 2014), abundancy, and high degree of reduction (Westbrook et al. 2019), resulting in high product yield compared to traditional sugars (Dharmadi et al. 2006). We also developed effective metabolic strategies for carbon flux direction via succinyl-CoA, a key precursor of the $\mathrm{C} 4$ pathway. The direction of dissimilated carbon toward succinyl-CoA is dependent on three oxygen-sensitive metabolic routes associated with the central metabolism, i.e., oxidative tricarboxylic acid (TCA) cycle, reductive TCA branch, and glyoxylate shunt (Fig. 1) (Cheng et al. 2013). Under oxygen-deprived (i.e., anaerobic) conditions, succinate (the precursor of succinyl-CoA) acts as an electron acceptor in place of oxygen and accumulates as a final product of mixed acid fermentation via the reductive TCA branch (Thakker et al. 2012). Under oxygen-rich (i.e., aerobic) conditions, succinate acts as a metabolic intermediate of the oxidative TCA cycle without accumulation, but it can also be alternatively derived via the glyoxylate shunt (Thakker et al. 2012). Here, we explored the manipulation of select genes involved in the TCA pathways and cultivation conditions to enhance carbon flux direction into the $\mathrm{C} 4$ pathway via succinyl-CoA.

To promote PBG accumulation, we had to limit the activity of subsequent PBG-consuming reactions toward porphyrins. Since porphyrin biosynthesis is essential for cell survival, knocking out any of these PBG-consuming reactions would be lethal (Mobius et al. 2010) (Leung et al. 2021). Hence, we applied Clustered Regularly Interspersed Short Palindromic Repeats interference (CRISPRi) (Qi et al. 2013) to repress the expression of hemC, whose encoding gene product of $\mathrm{HemC}$ mediates the conversion of PBG to $\mathrm{HMB}$, with minimal impact to cell physiology. To further enhance PBG biosynthesis and accumulation under the hemC-repressed genetic background, we also conducted heterologous co-expression of hemA from $R$. spheroides and the native hemB. In summary, we demonstrated the application of integrated strain engineering and bioprocessing strategies to enhance biosynthesis and ultimate extracellular accumulation of PBG, with systematic identification of potential biochemical, genetic, and metabolic factors limiting PBG production for characterization.

\section{Materials and methods}

\section{Bacterial strains and plasmids}

All bacterial strains and plasmids used in this study are listed in Table 1. Isolation of Genomic DNA from bacterial cells was performed using the Blood \& Tissue DNA Isolation Kit (Qiagen, Hilden, Germany). Standard recombinant DNA technologies were applied for molecular cloning (Miller 1992). Phusion and Taq DNA polymerase were obtained from New England Biolabs (Ipswich, MA, USA). All synthesized oligonucleotides were ordered from Integrated DNA Technologies (Coralville, IA, USA). DNA sequencing was performed by the Centre for Applied Genomics at the Hospital for Sick Children (Toronto, Canada). E. coli BW25113 was the parental strain for derivation of all engineered strains in this study and DH $5 \alpha$ was used as an E. coli host for molecular cloning. The $l d h A$ gene encoding lactate dehydrogenase (LDH) was previously inactivated in BW25113, generating BW $\Delta l d h A$ (Srirangan et al. 2014), a strain with much lower byproduct metabolite production.

Genetic implementation of the Shemin/C4 pathway in BW $\Delta l d h A$ was previously described (Miscevic et al. 2021). Heterologous expression of the hemA gene cloned in the pK184 vector was under the control of the $\mathrm{P}_{l a c}$ promoter. For heterologous co-expression of hemA and hemB in BW $\Delta l d h A$, the native E. coli hemB gene was first amplified by polymerase chain reaction (PCR) using the primer set g-hemA-hemB and the genomic DNA of $\mathrm{BW} \triangle l d h A$ as the template. The amplified hemB gene was Gibson-assembled with PCR-linearized pK184-hemA using the primer set g-pK-hemA-hemB to generate the plasmid pK184-hemA-hemB. Heterologous co-expression of the hemA and hemB genes cloned in the pK184 vector was also under the control of the $\mathrm{P}_{l a c}$ promoter.

Gene knockouts, including $s d h A$ (encoding succinate dehydrogenase (SDH) complex flavoprotein subunit $\mathrm{A}, \mathrm{SdhA}$ ) and $i c l R$ (encoding transcriptional AceBAK operon repressor, IclR), were introduced into $\mathrm{BW} \Delta l d h A$ by $\mathrm{P} 1$ phage transduction (Miller 1992) using the appropriate Keio Collection strains (The Coli Genetic Stock Center, Yale University, New Haven, CT, USA) as donors (Baba et al. 2006). For eliminating the co-transduced FRT-Kn ${ }^{\mathrm{R}}$-FRT cassette, the transductants were transformed with pCP20 (Cherepanov and Wackernagel 1995), a temperature-sensitive plasmid expressing a flippase (Flp) recombinase. After Flp-mediated excision of the $\mathrm{Kn}^{\mathrm{R}}$ cassette, a single Flp recognition site (FRT "scar site") was generated. The pCP20-containing cells were cured by incubation at $42{ }^{\circ} \mathrm{C}$. The genotypes of derived knockout strains were confirmed by colony PCR using the appropriate verification primer sets (Additional file 1: Table S1).

Expression of the hemC was repressed by CRISPRi using various derived plasmids from pdcas9-bacteria (Addgene plasmid \#44249) and pgRNA-bacteria (Addgene plasmid \#44251). The web tool ChopChop (Labun et al. 2016) was used to design sgRNAs with hem $C$-targeting sequences based on predicted expression efficiencies ranging from approximately 20 to 70\% (Additional file 1: Table S2). All synthesized 
Table 1 E. coli strains and plasmids used in this study

\begin{tabular}{|c|c|c|}
\hline Name & Description or relevant genotype & Source \\
\hline \multicolumn{3}{|l|}{ E. coli host strains } \\
\hline $\mathrm{DH} 5 \mathrm{a}$ & 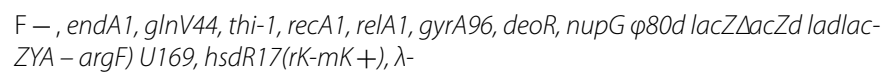 & Lab stock \\
\hline BW25113 & F-, $\Delta(\operatorname{araD}-\operatorname{araB}) 567, \Delta a c Z 4787(: . r r n B-3), \lambda-, r p h-1, \Delta(r h a D-r h a B) 568$, hsdR5 14 & (Datsenko and Wanner 2000) \\
\hline BW $\triangle l d h A$ & BW25113/dhA null mutant & (Srirangan et al. 2014) \\
\hline $\mathrm{DMH}$ & BW $\triangle / d h A / p K-h e m A$ & (Miscevic et al. 2021) \\
\hline $\mathrm{DMH} \triangle s d h A$ & sdhA null mutant of DMH & (Miscevic et al. 2021) \\
\hline $\mathrm{DMH} \triangle i \mathrm{I} / \mathrm{R}$ & iclR null mutant of $\mathrm{DMH}$ & This study \\
\hline $\mathrm{DMH} \triangle i \mathrm{i} / \mathrm{R} \Delta \mathrm{s} d h \mathrm{~A}$ & $i d / R$ and $s d h A$ mutants of $\mathrm{DMH}$ & (Miscevic et al. 2021) \\
\hline $\mathrm{DMH}-\mathrm{D} 9 \Delta \mathrm{s} d h \mathrm{~A}$ & $\mathrm{DMH} \Delta s d h A /$ pK-hemA/pgRNA-D9/pdcas9-bacteria & This study \\
\hline DMH-D9 $\Delta i c l R \Delta s d h A$ & DMH $\Delta i c / R \Delta s d h A / p K-h e m A / p g R N A-D 9 / p d c a s 9-b a c t e r i a$ & This study \\
\hline DSL & BW $\Delta /$ dhA/pK-hemA-hemB & This study \\
\hline DSL $\triangle s d h A$ & sdhA null mutant of DSL & This study \\
\hline DSL $\triangle i C I R$ & iclR null mutant of DSL & This study \\
\hline DSL $\triangle i C l R \triangle S d h A$ & $i c / R$ and $s d h A$ mutants of DSL & This study \\
\hline DSL-D9 $\triangle s d h A$ & DSL $\triangle$ sdhA/pK-hemA-hemB/pgRNA-D9/pdcas9-bacteria & This study \\
\hline 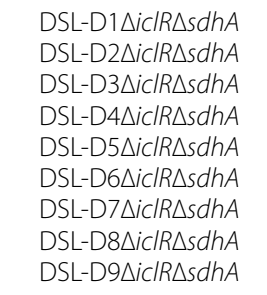 & 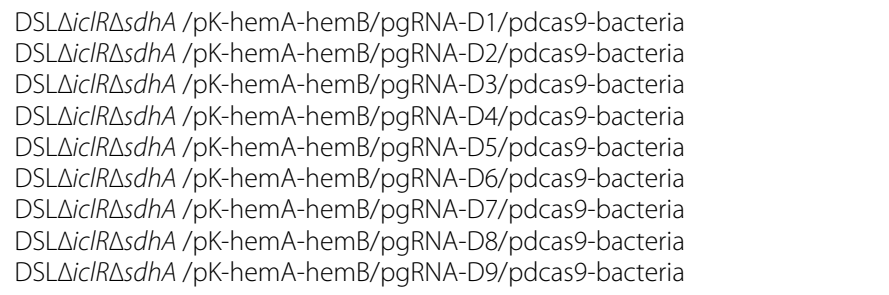 & $\begin{array}{l}\text { This study } \\
\text { This study } \\
\text { This study } \\
\text { This study } \\
\text { This study } \\
\text { This study } \\
\text { This study } \\
\text { This study } \\
\text { This study }\end{array}$ \\
\hline \multicolumn{3}{|l|}{ Plasmids } \\
\hline $\begin{array}{l}\text { pCP20 } \\
\text { pK184 }\end{array}$ & $\begin{array}{l}\text { Flp }+, \lambda \text { cl857+, } \lambda \text { pR Rep(pSC101 ori)ts, ApR, CmR } \\
\text { p15A ori, KmR, Plac:.lacZ' }\end{array}$ & $\begin{array}{l}\text { (Cherepanov and Wackernagel 1995) } \\
\text { (Jobling and Holmes 1990) }\end{array}$ \\
\hline pdcas9-bacteria & p15A ori, $\mathrm{P}_{\text {Tet }}$-dCas9 & (Qi et al. 2013) \\
\hline pgRNA-bacteria & ColE1 origin, $P_{J 23119}-g R N A$ & (Qi et al. 2013) \\
\hline $\begin{array}{l}\text { pgRNA-D1 } \\
\text { pgRNA-D2 } \\
\text { pgRNA-D3 } \\
\text { pgRNA-D4 } \\
\text { pgRNA-D5 } \\
\text { pgRNA-D6 } \\
\text { pgRNA-D7 } \\
\text { pgRNA-D8 } \\
\text { pgRNA-D9 }\end{array}$ & $\begin{array}{l}\text { Derived from pgRNA-bacteria, } P_{\text {spe }}:: h e m C-g R N A-D 1 \\
\text { Derived from pgRNA-bacteria, } P_{\text {spe }}: \text { hemC-gRNA-D2 } \\
\text { Derived from pgRNA-bacteria, } P_{\text {spe }}: \text { hemC-gRNA-D3 } \\
\text { Derived from pgRNA-bacteria, } P_{\text {spe }}: \text { hemC-gRNA-D4 } \\
\text { Derived from pgRNA-bacteria, } P_{\text {spel }}: \text { hemC-gRNA-D5 } \\
\text { Derived from pgRNA-bacteria, } P_{\text {spe }}: \text { hemC-gRNA-D6 } \\
\text { Derived from pgRNA-bacteria, } P_{\text {spe }}: \text { hemC-gRNA-D7 } \\
\text { Derived from pgRNA-bacteria, } P_{\text {spe }}: \text { hemC-gRNA-D8 } \\
\text { Derived from pgRNA-bacteria, } P_{\text {spe }}: \text { hemC-gRNA-D9 }\end{array}$ & $\begin{array}{l}\text { This study } \\
\text { This study } \\
\text { This study } \\
\text { This study } \\
\text { This study } \\
\text { This study } \\
\text { This study } \\
\text { This study } \\
\text { This study }\end{array}$ \\
\hline pK-hemA & Derived from pK184, $\mathrm{P}_{\text {lac }}:$ hemA & (Miscevic et al. 2021) \\
\hline pK-hemA-hemB & Derived from pK184, $\mathrm{P}_{\text {lac }}$ :hemA-hemB & This study \\
\hline
\end{tabular}

oligonucleotide pairs have 60 nucleotides (nt), which include $20 \mathrm{nt}$ hem $\mathrm{C}$-targeting sequence, $20 \mathrm{nt}$ upstream and $20 \mathrm{nt}$ downstream sequences of pgRNA-bacteria vector (Fig. 2). They were annealed as described previously (Pengpumkiat et al. 2016), generating doublestranded DNA fragments. These DNA fragments were then individually Gibson-assembled with the PCR-linearized pgRNA-bacteria using the primer set g-pgRNA to generate plasmids, such as pgRNA-D9 (Table 1 ). The hem $C$-repressed strains can be developed based on a triple-plasmid system (Fig. 2) containing pK184-hemA (or pK184-hemA-hemB), pdcas9-bacteria, and the gRNA-containing plasmid (such as pgRNA-D9).

\section{Media and bacterial cell cultivation}

All medium components were obtained from SigmaAldrich Co. (St Louis, MO, USA) except yeast extract and tryptone which were obtained from BD Diagnostic Systems (Franklin Lakes, NJ, USA). E. coli strains, stored as glycerol stocks at $-80{ }^{\circ} \mathrm{C}$, were streaked on lysogeny broth (LB; $10 \mathrm{~g} \mathrm{~L}^{-1}$ tryptone, $5 \mathrm{~g} \mathrm{~L}^{-1}$ yeast extract, and $5 \mathrm{~g} \mathrm{~L}^{-1} \mathrm{NaCl}$ ) agar plates with appropriate antibiotics 

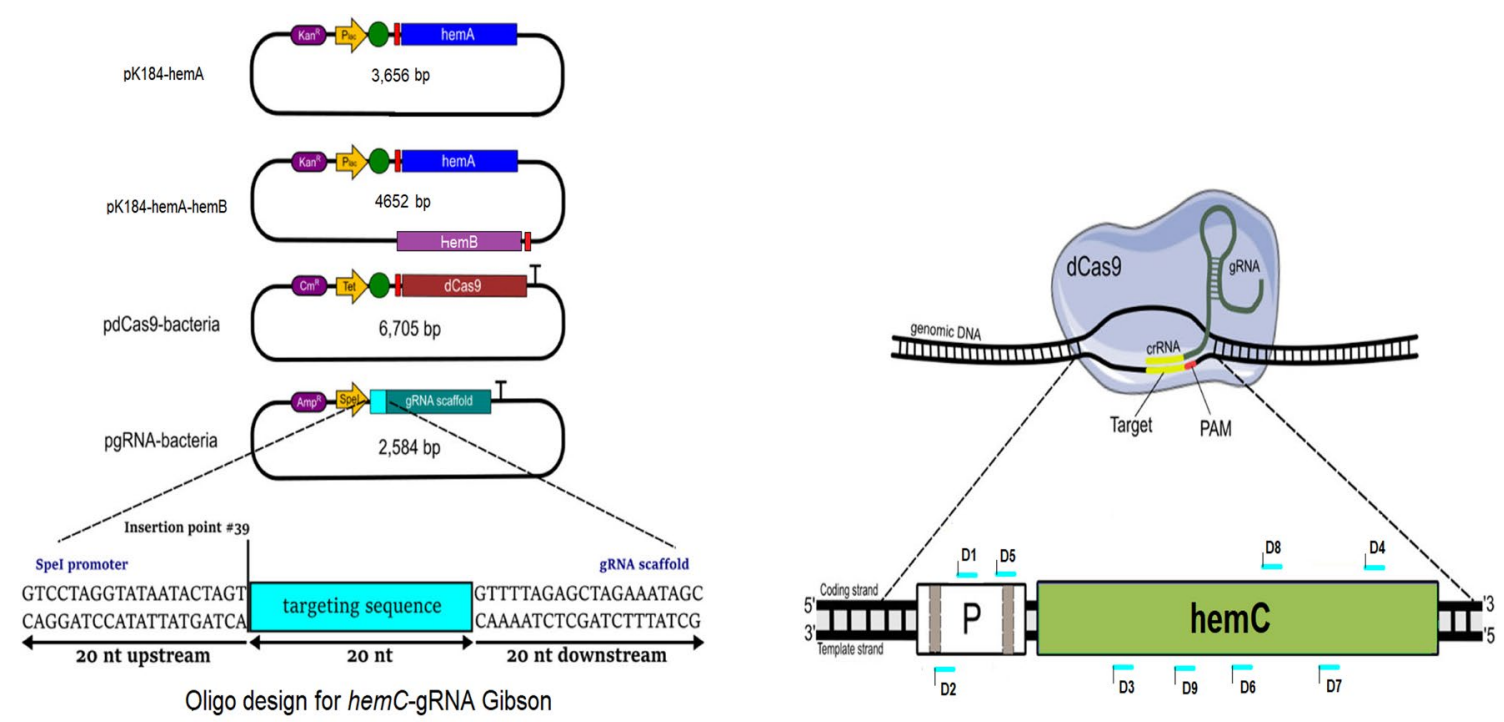

$$
\begin{aligned}
& \Rightarrow \text { Transcriptional promoter } \square 20 \mathrm{nt} \text { targeting-sequence } \\
& \text { Transcriptional operator I Ribosome binding site } \\
& \text { Resistance marker } \quad T \text { Transcriptional terminato }
\end{aligned}
$$

Fig. 2 Molecular strategy for CRISPRi-based hemC repression. The four plasmids with their major genetic features, such as promoters, antibiotic resistance markers, key genes, for CRISPRi are shown. Select hemC-targeting sequences and their associated positions in the hemC gene (i.e., D1, D2, D3, D4, D5, D6, D7, D8, and D9) are shown as well. Note that the sequence location, GC content, and predicted hemC expression efficiency for various hemC-targeting sequences are shown in Additional file 1, in which select hemC-repressed strains derived from DSL $\triangle$ icIR $\triangle$ sdhA were characterized for quantification of the relative hemC mRNA level using qRT-PCR compared to the control DSL $\triangle i c I R \triangle s d h A$. All qRT-PCR experiments were conducted in duplicate

[ampicillin (100 $\left.\mathrm{mg} \mathrm{L}^{-1}\right)$, kanamycin $\left(50 \mathrm{mg} \mathrm{L}^{-1}\right)$, and chloramphenicol $\left(25 \mathrm{mg} \mathrm{L}^{-1}\right)$ ] and incubated at $37^{\circ} \mathrm{C}$ for $14-16 \mathrm{~h}$.

For shake-flask cultivations, single colonies were picked from LB plates to inoculate $30 \mathrm{~mL} \mathrm{LB}$ medium in $125-\mathrm{mL}$ conical flasks. The cultures were shaken at $37^{\circ} \mathrm{C}$ and $280 \mathrm{rpm}$ in a rotary shaker (New Brunswick Scientific, NJ, USA) and used as seed cultures to inoculate $220 \mathrm{~mL} \mathrm{LB}$ media at $1 \%(\mathrm{v} / \mathrm{v})$ in $1-\mathrm{L}$ conical flasks with appropriate antibiotics. This second seed culture was shaken at $37^{\circ} \mathrm{C}$ and $280 \mathrm{rpm}$ until the cell density reached $0.80 \mathrm{OD}_{600}$. Cells were then harvested by centrifugation at $9,000 \times \mathrm{g}$ and $20{ }^{\circ} \mathrm{C}$ for $10 \mathrm{~min}$ and resuspended in $30 \mathrm{~mL}$ modified $\mathrm{M} 9$ production medium. The suspended culture was transferred into $125-\mathrm{mL}$ screwed cap plastic flasks for shaking at $37{ }^{\circ} \mathrm{C}$ at $280 \mathrm{rpm}$ in a rotary shaker. Unless otherwise specified, the modified M9 production medium contained $25 \mathrm{~g} \mathrm{~L}^{-1}$ glycerol, $5 \mathrm{~g} \mathrm{~L}^{-1}$ yeast extract, $10 \mathrm{mM} \mathrm{NaHCO}, 1 \mathrm{mM} \mathrm{MgCl}$, $200 \mathrm{~mL} \mathrm{~L}^{-1}$ of M9 salts mix (33.9 g L $\mathrm{g}^{-1} \mathrm{Na}_{2} \mathrm{HPO}_{4}, 15 \mathrm{~g}$ $\left.\mathrm{L}^{-1} \mathrm{KH}_{2} \mathrm{PO}_{4}, 5 \mathrm{~g} \mathrm{~L}^{-1} \mathrm{NH}_{4} \mathrm{Cl}, 2.5 \mathrm{~g} \mathrm{~L}^{-1} \mathrm{NaCl}\right), 1 \mathrm{~mL} \mathrm{~L}^{-1}$ dilution of Trace Metal Mix A5 $\left(2.86 \mathrm{~g} \mathrm{~L}^{-1} \mathrm{H}_{3} \mathrm{BO}_{3}, 1.81 \mathrm{~g}\right.$ $\mathrm{L}^{-1} \mathrm{MnCl}_{2} \bullet 4 \mathrm{H}_{2} \mathrm{O}, 0.222 \mathrm{~g} \mathrm{~L}^{-1} \mathrm{ZnSO}_{4} \cdot 7 \mathrm{H}_{2} \mathrm{O}, 0.39 \mathrm{~g} \mathrm{~L}^{-1}$
$\mathrm{Na}_{2} \mathrm{MoO}_{4} \cdot 2 \mathrm{H}_{2} \mathrm{O}, 79 \mu \mathrm{g} \mathrm{L}^{-1} \mathrm{CuSO}_{4} \cdot 5 \mathrm{H}_{2} \mathrm{O}, 49.4 \mu \mathrm{g} \mathrm{L}^{-1}$ $\left.\mathrm{Co}\left(\mathrm{NO}_{3}\right)_{2} \cdot 6 \mathrm{H}_{2} \mathrm{O}\right)$, and was supplemented with $0.1 \mathrm{mM}$ isopropyl $\beta$-D-1-thiogalactopyranoside (IPTG).

For bioreactor cultivation, single colonies were picked from LB plates to inoculate $30 \mathrm{~mL}$ super broth (SB) medium (32 $\mathrm{g} \mathrm{L}^{-1}$ tryptone, $20 \mathrm{~g} \mathrm{~L}^{-1}$ yeast extract, and $5 \mathrm{~g} \mathrm{~L}^{-1} \mathrm{NaCl}$ ) in $125 \mathrm{~mL}$ conical flasks. The overnight cultures were shaken at $37{ }^{\circ} \mathrm{C}$ and $280 \mathrm{rpm}$ in a rotary shaker (New Brunswick Scientific, NJ, USA) and used as seed cultures to inoculate $220 \mathrm{~mL}$ SB media at $1 \%(\mathrm{v} / \mathrm{v})$ in $1-\mathrm{L}$ conical flasks with appropriate antibiotics. This second seed cultures were shaken at $37{ }^{\circ} \mathrm{C}$ and $280 \mathrm{rpm}$ for $14-16 \mathrm{~h}$. Cells were then harvested by centrifugation at $9,000 \times \mathrm{g}$ and $20^{\circ} \mathrm{C}$ for $10 \mathrm{~min}$ and resuspended in $50 \mathrm{~mL}$ fresh LB media. The suspended culture was used to inoculate a 1-L stirred tank bioreactor (containing two Rushton radial flow disks as impellers) (CelliGen 115, Eppendorf AG, Hamburg, Germany) at $37{ }^{\circ} \mathrm{C}$ and $430 \mathrm{rpm}$. The semidefined production medium in the batch bioreactor contained $30 \mathrm{~g} \mathrm{~L}^{-1}$ glycerol, $0.23 \mathrm{~g} \mathrm{~L}^{-1} \mathrm{~K}_{2} \mathrm{HPO}_{4}, 0.51 \mathrm{~g}$ $\mathrm{L}^{-1} \mathrm{NH}_{4} \mathrm{Cl}$, $49.8 \mathrm{mg} \mathrm{L}^{-1} \mathrm{MgCl}_{2}$, $48.1 \mathrm{mg} \mathrm{L}^{-1} \mathrm{~K}_{2} \mathrm{SO}_{4}$, $1.52 \mathrm{mg} \mathrm{L}^{-1} \mathrm{FeSO}_{4}, 0.055 \mathrm{mg} \mathrm{L}{ }^{-1} \mathrm{CaCl}_{2}, 2.93 \mathrm{~g} \mathrm{~L}^{-1}$ 
$\mathrm{NaCl}, 0.72 \mathrm{~g} \mathrm{~L}^{-1}$ tricine, $10 \mathrm{~g} \mathrm{~L}^{-1}$ yeast extract, $10 \mathrm{mM}$ $\mathrm{NaHCO}_{3}$, and $1 \mathrm{~mL} \mathrm{~L}^{-1}$ trace elements $\left(2.86 \mathrm{~g} \mathrm{~L}^{-1}\right.$ $\mathrm{H}_{3} \mathrm{BO}_{3}, 1.81 \mathrm{~g} \mathrm{~L}^{-1} \mathrm{MnCl}_{2} \bullet 4 \mathrm{H}_{2} \mathrm{O}, 0.222 \mathrm{~g} \mathrm{~L}^{-1} \mathrm{ZnSO}_{4}$ • $7 \mathrm{H}_{2} \mathrm{O}, 0.39 \mathrm{~g} \mathrm{~L}^{-1} \mathrm{Na}_{2} \mathrm{MoO}_{4} \cdot 2 \mathrm{H}_{2} \mathrm{O}, 79 \mu \mathrm{g} \mathrm{L}^{-1} \mathrm{CuSO}_{4}$ • $5 \mathrm{H}_{2} \mathrm{O}, 49.4 \mu \mathrm{g} \mathrm{L}^{-1} \mathrm{Co}\left(\mathrm{NO}_{3}\right)_{2} \cdot 6 \mathrm{H}_{2} \mathrm{O}$ ) (Neidhardt et al. 1974), and was supplemented with $0.1 \mathrm{mM}$ isopropyl $\beta$-D-1-thiogalactopyranoside (IPTG). Aerobic and microaerobic conditions were maintained by purging air into the bulk culture at $1 \mathrm{vvm}$ and into the headspace at $0.1 \mathrm{vvm}$, respectively. The $\mathrm{pH}$ of the media was maintained at $7.0 \pm 0.1$ with $30 \%(\mathrm{v} / \mathrm{v}) \mathrm{NH}_{4} \mathrm{OH}$ and $15 \%(\mathrm{v} / \mathrm{v}) \quad \mathrm{H}_{3} \mathrm{PO}_{4}$ throughout the bioreactor cultivation.

\section{Analysis}

Culture samples were diluted with $0.15 \mathrm{M}$ saline solution for measuring cell density in $\mathrm{OD}_{600}$ using a spectrophotometer (DU520, Beckman Coulter, Fullerton, CA). Cell-free medium (Additional file 1: Table S3) was prepared by centrifugation of the culture sample at $9000 \times g$ for $5 \mathrm{~min}$ and filter sterilization using a $0.2-\mu \mathrm{M}$ syringe filter. The quantification of extracellular metabolites and glycerol was conducted using high-performance liquid chromatography (HPLC) (LC10AT, Shimadzu, Kyoto, Japan) with a refractive index detector (RID; RID-10A, Shimadzu, Kyoto, Japan) and a chromatographic column (Aminex HPX-87H, Bio-Rad Laboratories, CA, USA). The HPLC column temperature was maintained at $35{ }^{\circ} \mathrm{C}$ and the mobile phase was $5 \mathrm{mM} \mathrm{H}_{2} \mathrm{SO}_{4}(\mathrm{pH} \mathrm{2})$ running at $0.6 \mathrm{~mL} \mathrm{~min}^{-1}$. The RID signal was acquired and processed by a data processing unit (Clarity Lite, DataApex, Prague, Czech Republic).

PBG titer in the cell-free medium was measured using a regular Ehrlich's reagent and PBG was colorimetrically quantified by taking an absorbance reading at $555 \mathrm{~nm}$ (Mauzerall and Granick 1956). The percentage yield of PBG was defined as the mole ratio of the produced PBG to the theoretically maximal PBG produced based on the consumed glycerol with a molar ratio of one-to-six (i.e., one-mole PBG is derived from six-mole glycerol). Note that one-mole succinyl-CoA (derived from two-mole glycerol) and one-mole glycine (derived from one-mole glycerol) generate one-mole 5-ALA, whereas two-mole 5-ALA forms one-mole PBG. The bulk level of porphyrin compounds in the cell-free medium was estimated using a spectrophotometer at two specific wavelengths, i.e., $405 \mathrm{~nm}$ (measuring Soret band) and $495 \mathrm{~nm}$ (measuring Q-band). Note that all bioreactor cultivation results shown in this study were, respectively, obtained from a single batch run, with most of cultivation batches being duplicated or even triplicated to ensure their data reproducibility.
Real-time quantitative reverse transcription PCR (qRT-PCR) For RNA extraction, $E$. coli cells were cultivated in $30 \mathrm{~mL}$ liquid $\mathrm{LB}$ medium at $37^{\circ} \mathrm{C}$ and harvested in the exponential growth phase. Total RNA isolation was done using the High Pure RNA Isolation Kit (Roche Diagnostics, Basel, Switzerland) as per manufacturer's instructions and stored at $-80{ }^{\circ} \mathrm{C}$ for later analysis. Complementary DNAs (cDNAs) were synthesized from $100 \mathrm{ng}$ of total RNA using the High-Capacity cDNA Reverse Transcription Kit (ThermoFisher Scientific, MA). Sequence-specific primers for $h e m C$ cDNA (i.e., $\mathrm{q}$-hemC) and internal control rrsA (encoding ribosomal RNA 16S) cDNA (i.e., q-rrsA) were used for real-time PCR amplification in $25 \mu \mathrm{L}$ reaction mixture. qRTPCR was carried out using the Power SYBR $^{\circledR}$ Green PCR Master Mix (ThermoFisher Scientific; MA) in an Applied Biosystems StepOnePlus ${ }^{\mathrm{TM}}$ System as per the manufacturer's instructions. All quantification experiments were performed in duplicate.

\section{Statistical analysis}

All experimental data in this study were collected in duplicate for statistical analysis. In addition, data comparison was statistically analyzed with an unpaired two-tail Student's $t$-test based on 95\% confidence level to ensure its statistical significance (Additional file 1: Table S4). Hence, $P<0.05$ was used as a standard criterion of statistical significance when comparing the means of experimental data, such as PBG titer.

\section{Results \\ Carbon flux direction from the TCA pathways to the Shemin/C4 pathway}

The Shemin/C4 pathway was implemented in E. coli via heterologous expression of hemA from $R$. sphaeroides in BW $\Delta l d h A$ (Miscevic et al. 2021). The resulting control strain, DMH, was cultivated under aerobic conditions in a batch bioreactor with $\sim 30 \mathrm{~g} \mathrm{~L}^{-1}$ of glycerol as the carbon source. The supply of excess oxygen supported cell growth with effective glycerol consumption, resulting in $120 \mathrm{mg} \mathrm{L}^{-1}$ of the peak PBG titer $(1.31 \%$ yield) with substantial acetate formation (69.3\% yield) (Fig. 3). Extending the cultivation, based on the remaining glycerol, and produced acetate, resulted in reduction of PBG titer to $75.1 \mathrm{mg} \mathrm{L}^{-1}$ (0.65\% yield) with increased porphyrin formation. While the formation of other byproduct metabolites, such as ethanol, succinate, and formate, was minimal, the results suggest the need for metabolic strategies to reduce carbon flux drainage toward acetogenesis and porphyrin biosynthesis for enhanced PBG accumulation. Note that bioreactor characterization was used in this study since 


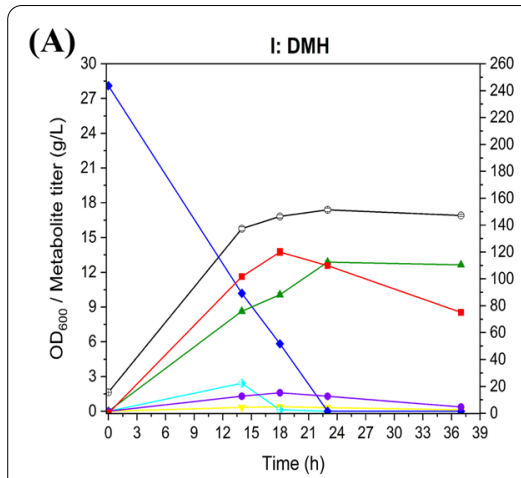

(B)

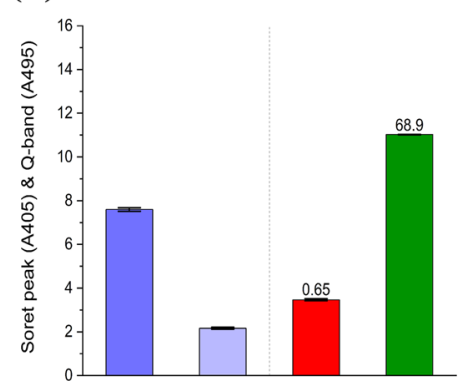

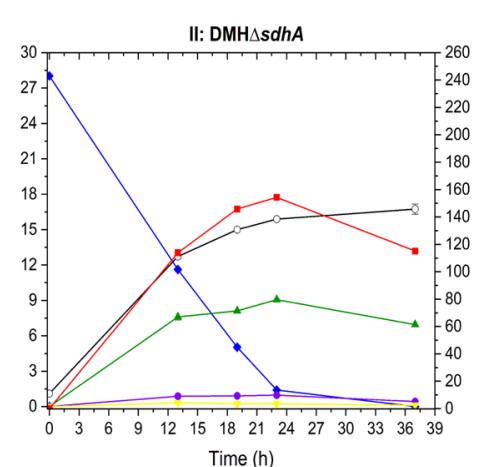

Time (h)

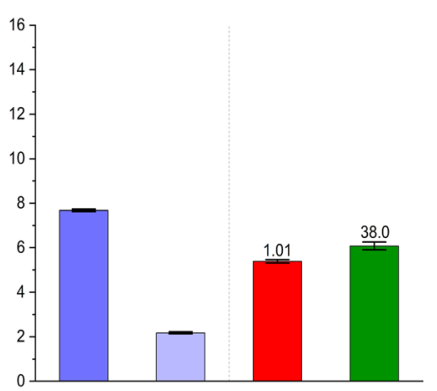

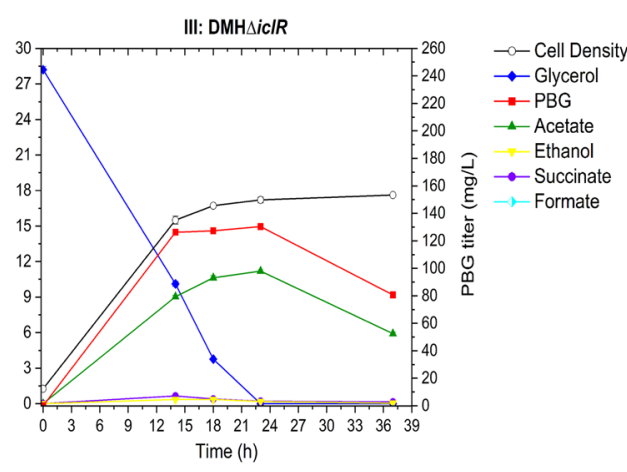

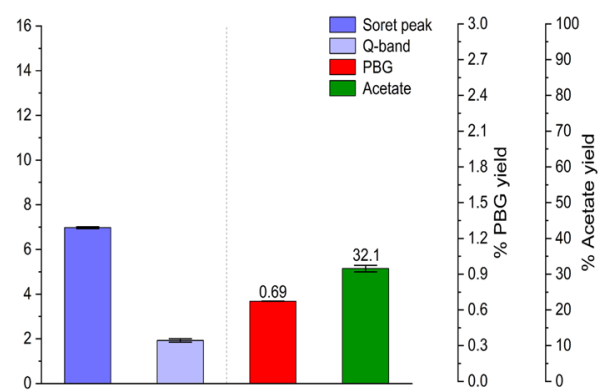

Fig. 3 Bioreactor cultivation of $D M H, D M H \triangle s d h A$, and DMH $\Delta i c / R$ for PBG biosynthesis under aerobic conditions. Time profiles of cell density $\left(\mathrm{OD}_{600}\right)$, glycerol consumption and metabolite production profiles, acetate and PBG percentage yields, and extracellular accumulation of porphyrins (represented by the absorbance readings of the Soret peak (A405) and Q-band (A495)) are shown. The percentage yields of acetate/PBG and absorbance readings of porphyrin compounds are calculated/measured based on the consumed glycerol at end of cultivation. (I) DMH, (II) $\mathrm{DMH} \Delta s d h A$, (III) DMH $\Delta i c / R$. All values are reported as means $\pm \mathrm{SD}(n=2)$ shake-flask cultivation resulted in minimal PBG biosynthesis and accumulation (data not shown).

PBG biosynthesis via the C4 pathway utilizes succinyl$\mathrm{CoA}$ as a key precursor (with the other being glycine) to produce 5-ALA as an intermediate before subsequent conversion to PBG. The intracellular succinyl-CoA supply is affected by three oxygen-sensitive metabolic routes associated with the central metabolism, i.e., oxidative TCA cycle, reductive TCA branch, and glyoxylate shunt (Fig. 1). Due to more effective cell growth and glycerol consumption, we first characterized our engineered strains under aerobic conditions. To direct more carbon flux toward the succinyl-CoA node, we inactivate the oxidative TCA cycle by knocking out the $s d h A$ gene, resulting in the mutant strain DMH $\Delta s d h A$, with an improved peak PBG titer of $154 \mathrm{mg} \mathrm{L}^{-1}$ (1.41\% yield) and $115 \mathrm{mg}$ $\mathrm{L}^{-1}(1.01 \%$ yield) at the end of bioreactor cultivation (Fig. 3). On the other hand, we also deregulated glyoxylate shunt by knocking out the iclR gene, resulting in the mutant strain DMH $\triangle i c l R$ in which more carbon flux could be directed toward the succinyl-CoA node via glyoxylate shunt with reduced decarboxylation through bypassing the oxidative TCA cycle. Aerobic bioreactor cultivation of DMH $\Delta i c l R$ also showed improved peak PBG titer of $130 \mathrm{mg} \mathrm{L}^{-1}$ (1.13\% yield) and $80.7 \mathrm{mg} \mathrm{L}^{-1}$
(0.69\% yield) at the end of the cultivation (Fig. 3). Both single-mutant strains of DMH $\Delta i c l R$ and $\mathrm{DMH} \Delta s d h A$ displayed effective cell growth and glycerol consumption, with reduced acetate production $(32.1 \%$ and $38.0 \%$ yield, respectively) compared to control strain $\mathrm{DMH}$.

Next, we derived the double-mutant strain $\mathrm{DMH} \Delta i c l R \Delta s d h A$ such that the carbon flux from the deregulated glyoxylate shunt could be further directed toward the succinyl-CoA mode via the reductive TCA branch for enhanced biosynthesis of PBG and porphyrins while minimizing decarboxylation. Aerobic bioreactor cultivation of DMH $\Delta i c l R \Delta s d h A$ produced $87.3 \mathrm{mg} \mathrm{L}^{-1}$ $(0.66 \%$ yield) at the end of cultivation (Fig. 4$)$. Moreover, we observed significantly reduced acetate formation with $35.9 \%$ yield, compared to the control strain DMH. These results indicate successful carbon flux direction from the TCA pathways to the C4 pathway in DMH $\Delta i c l R \Delta s d h A$. However, the directed carbon flux appeared to proceed toward porphyrin formation rather than PBG accumulation in these engineered strains, as indicated by subsequent reduction in PBG titer after reaching a peak value. While blocking the conversion of PBG to HMB by knocking out hemC appears to be a feasible way to promote PBG accumulation, such gene knockout is lethal due to physiological requirement of essential porphyrins. 


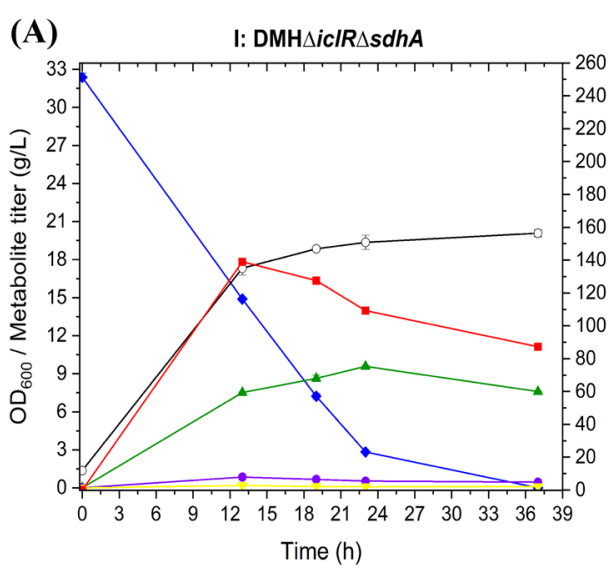

(B)
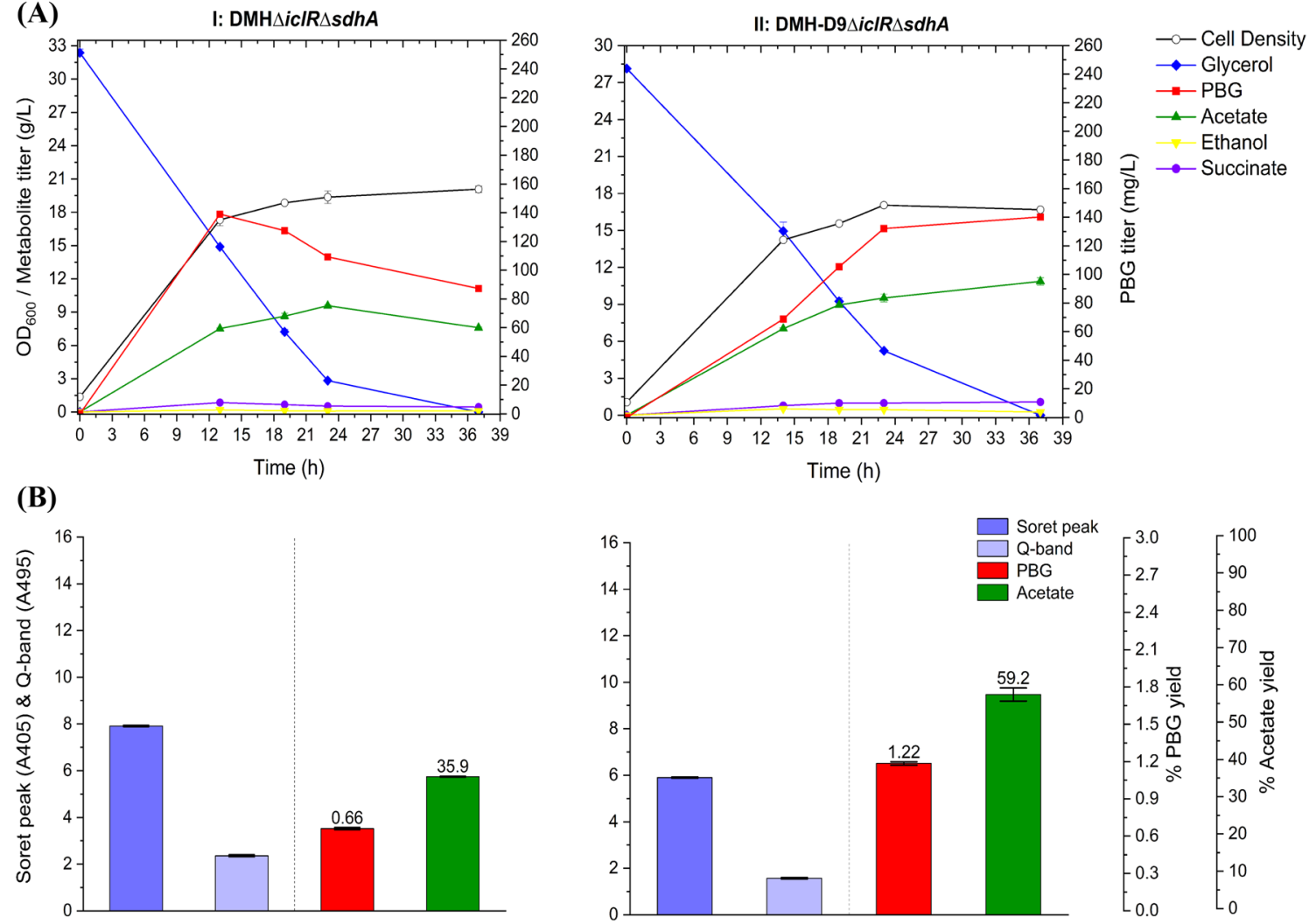

Fig. 4 Bioreactor cultivation of DMH $\Delta i c / R \Delta s d h A$ and DMH-D9 $\Delta i c l R \Delta s d h A$ for PBG biosynthesis under aerobic conditions. Time profiles of cell density $\left(\mathrm{OD}_{600}\right)$, glycerol consumption and metabolite production profiles, acetate and PBG percentage yields, and extracellular accumulation of porphyrins (represented by the absorbance readings of the Soret peak (A405) and Q-band (A495)) are shown. The percentage yields of acetate/ PBG and absorbance readings of porphyrin compounds are calculated/measured based on the consumed glycerol at end of cultivation. Final

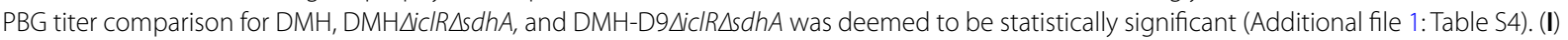

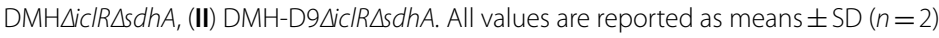

\section{Repression of hemC expression for PBG biosynthesis and accumulation}

Since hemC is essential for heme biosynthesis, gene knockdown to repress hemC expression was explored to promote PBG accumulation with minimal impact on cell physiology and PBG biosynthesis. Hence, CRISPRi was applied using hemC-targeting gRNAs with distinct expression efficiencies (predicted by CHOPCHOP). Upon first screening of a selection of gRNAs targeting different areas of hemC (Fig. 2; Additional file 1: Table S2) based on bioreactor cultivation, hemC-gRNA-D9 appeared to show effective hem $C$ repression with enhanced PBG biosynthesis and accumulation. The hemC-repression effect was further verified by qRT-PCR (Additional file 1: Figs. $\mathrm{S} 1$ and S2). Hence, the resulting hem $\mathrm{C}$-repressed strains based on the use of hemC-gRNA-D9 were selected for complete bioreactor characterization. Under aerobic bioreactor conditions, cell growth and glycerol utilization for DMH-D9 $\Delta i c l R \Delta s d h A$ were minimally affected compared to the control strain DMH $\Delta i c l R \Delta s d h A$, suggesting that the need of essential porphyrins for cell survival was properly met in the presence of hem $C$ repression. Importantly, we observed more effective biosynthesis and accumulation of PBG, achieving a peak/final titer of $140 \mathrm{mg}$ $\mathrm{L}^{-1}$ (1.22\% yield) at the end of the cultivation (Fig. 4). Note that the Soret peak and Q-band absorbance values of the cell-free medium for the culture sample of DMHD9 $\triangle i c l R \Delta s d h A$ was reduced to some extent, suggesting successful hem $C$ repression with reduced porphyrin formation.

\section{Increasing hemB expression to enhance PBG biosynthesis and accumulation}

To further enhance PBG biosynthesis and accumulation, we cloned the native hemB gene from $E$. coli for heterologous expression along with hemA from $R$. sphaeroides, resulting in another control strain DSL. While aerobic bioreactor cultivation of DSL led to a much higher peak PBG titer compared to DMH, the PBG titer reduced rapidly upon extended cultivation to $65.7 \mathrm{mg} \mathrm{L}^{-1}(0.52 \%$ 
yield) (Fig. 5), a level similar to DMH. Porphyrin biosynthesis in DSL appeared to be higher than DMH, as evidenced by higher Soret peak and Q-band absorbance values of the cell-free medium for the culture sample. Also note that cell growth and glycerol consumption remained effective for DSL compared to DMH.

Similar to $\mathrm{DMH}$, the metabolic limitations associated with excessive carbon flux drainage toward acetogenesis and porphyrin formation in DSL should be addressed. We derived single-mutant strains of DSL $\Delta s d h A$ and DSL $\triangle i c l R$ with the $s d h A$ and iclR gene knockouts, respectively. While these single-mutant strains did not improve PBG biosynthesis significantly upon aerobic bioreactor cultivation, they showed metabolic effects similar to the corresponding DMH single-mutant strains (Fig. 5). We further derived the double-mutant strain DSL $\Delta i c l R \Delta s d h A$, which showed significantly enhanced PBG biosynthesis compared to the DSL control and single-mutant strains upon aerobic bioreactor cultivation, i.e., a PBG titer of $104 \mathrm{mg} \mathrm{L}^{-1}$ ( $0.81 \%$ yield) at the end of the cultivation (Fig. 6). Moreover, reduced acetogenesis was observed in DSL $\Delta i c l R \Delta s d h A$ with effective glycerol utilization and cell growth, suggesting successful carbon flux direction towards the succinyl-CoA node for
PBG and porphyrin biosynthesis under this new genetic background.

Furthermore, hemC-gRNA-D9 was used to repress hem $C$ expression in the double-mutant strain DSL $\Delta i c l R \Delta s d h A$, resulting in DSL-D9 $\Delta i c l R \Delta s d h A$. Aerobic bioreactor cultivation of DSL-D9 $\Delta i c l R \Delta s d h A$ showed much improved PBG biosynthesis and accumulation, i.e., a PBG titer at $209 \mathrm{mg} \mathrm{L}^{-1}$ (1.73\% yield) at the end of the cultivation, though glycerol consumption and cell growth were slightly affected. Note that the final PBG yield for DSL-D9AiclR $\Delta s d h A$ was 2.14-fold that for the control DSL $\Delta i c l R \Delta s d h A$, suggesting the effectiveness of hem $C$ repression toward enhanced PBG biosynthesis and accumulation.

\section{Strain engineering for PBG biosynthesis under microaerobic conditions}

Using engineered strains with the single $s d h A$ mutation, we also explored PBG biosynthesis under oxygen-limited (i.e., microaerobic) conditions. Due to the inactivated oxidative TCA cycle with a regulated glyoxylate shunt, cell growth and glycerol utilization under microaerobic conditions for these control and mutant strains were ineffective compared to aerobic cultivation. In
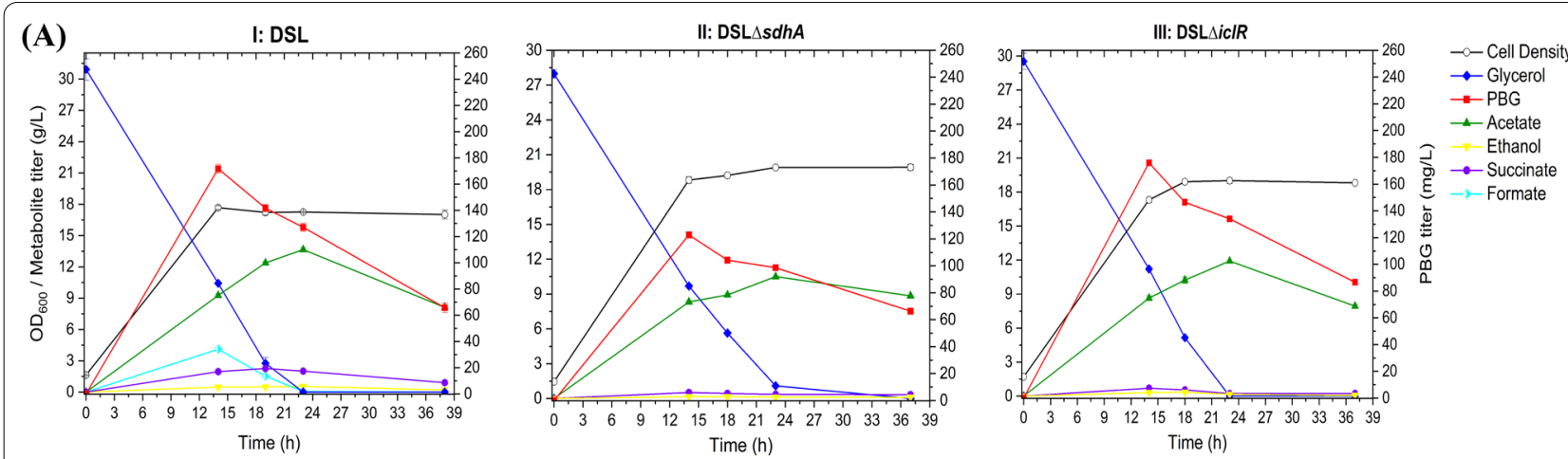

(B)
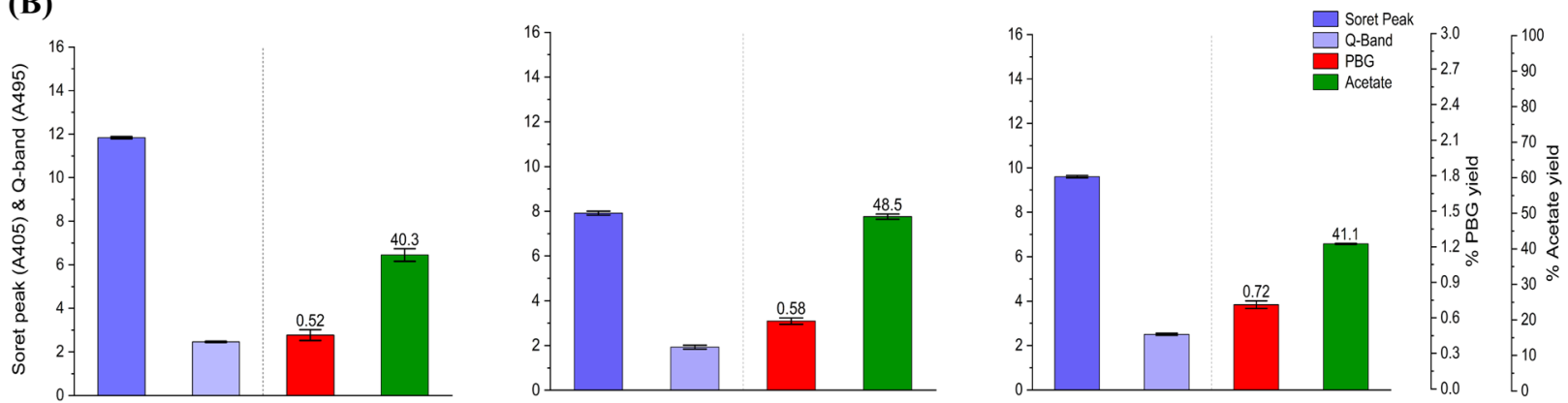

Fig. 5 Bioreactor cultivation of DSL, DSL $\triangle s d h A$, and DSL $\triangle c / R$ for PBG biosynthesis under aerobic conditions. Time profiles of cell density $\left(\mathrm{OD}_{600}\right)$, glycerol consumption and metabolite production profiles, acetate and PBG percentage yields, and extracellular accumulation of porphyrins (represented by the absorbance readings of the Soret peak (A405) and Q-band (A495)) are shown. The percentage yields of acetate/PBG and absorbance readings of porphyrin compounds are calculated/measured based on the consumed glycerol at end of cultivation. (I) DSL, (II) $\mathrm{DSL} \triangle s d h A$, (III) DSL $\Delta i c l R$. All values are reported as means $\pm S D(n=2)$ 

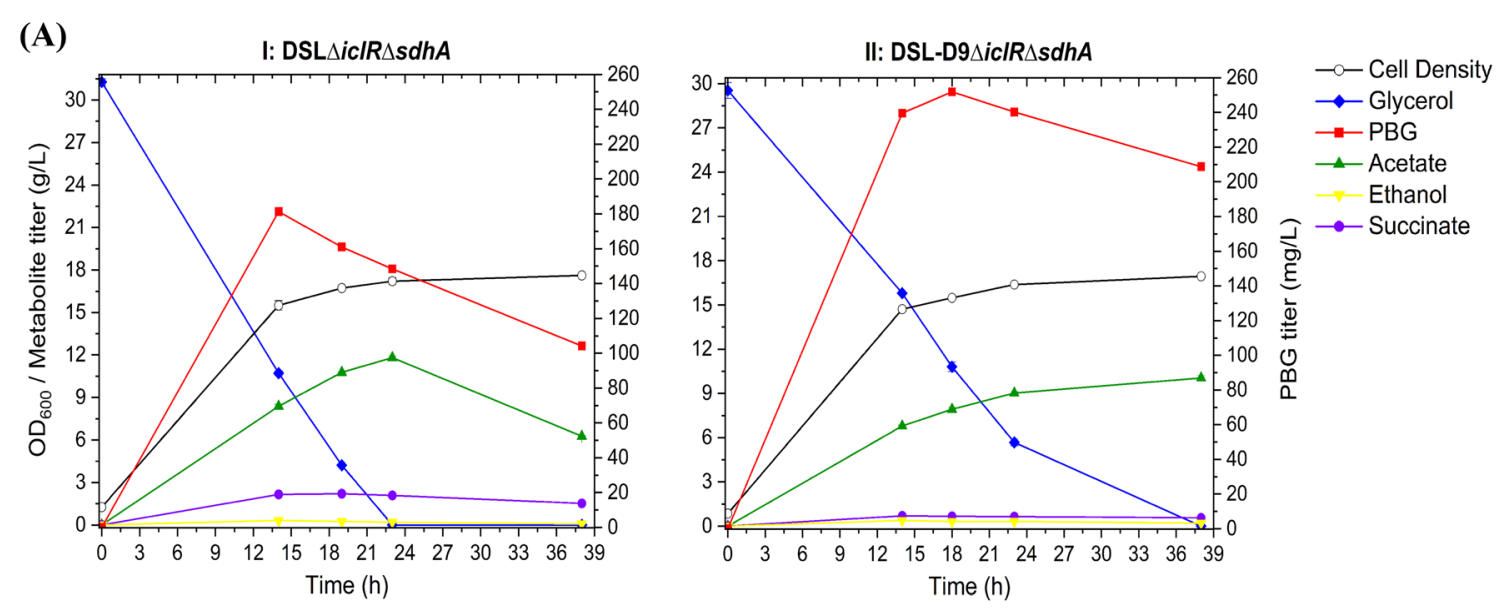

(B)
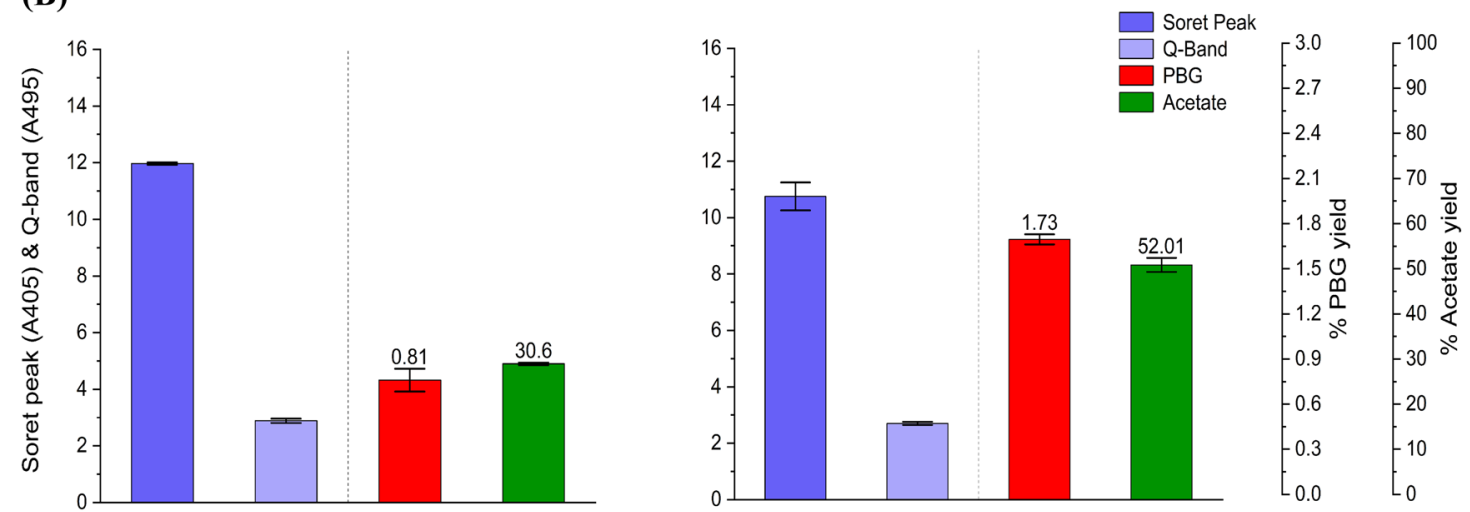

Fig. 6 Bioreactor cultivation of DSL $\Delta i c l R \Delta s d h A$ and DSL-D9 $\Delta i c / R \Delta s d h A$ for PBG biosynthesis under aerobic conditions. Time profiles of cell density $\left(\mathrm{OD}_{600}\right)$, glycerol consumption and metabolite production profiles, acetate and PBG percentage yields, and extracellular accumulation of porphyrins (represented by the absorbance readings of the Soret peak (A405) and Q-band (A495)) are shown. The percentage yields of acetate/PBG and absorbance readings of porphyrin compounds are calculated/measured based on the consumed glycerol at end of cultivation. Final PBG titer

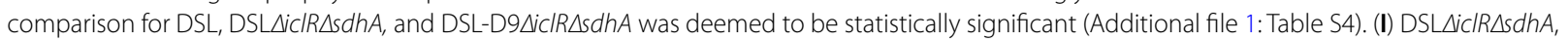

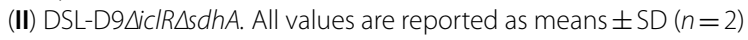

general, PBG biosynthesis under microaerobic conditions was also ineffective compared to aerobic cultivation. For the control strain DMH, the final PBG titer for microaerobic bioreactor cultivation was lower than that for aerobic cultivation, only reaching $48.7 \mathrm{mg}$ $\mathrm{L}^{-1}$ (0.41\% yield) (Fig. 7), with poor glycerol utilization and cell growth. Interestingly, porphyrin biosynthesis under microaerobic conditions appeared to be more effective, as evidenced by higher Soret peak and Q-band absorbance values, than aerobic cultivation. Compared to the control strain DMH, PBG biosynthesis under microaerobic conditions for the singlemutant strain $\mathrm{DMH} \Delta s d h A$, in which only the reductive TCA branch was functional, was slightly improved, reaching a final PBG titer of $55.9 \mathrm{mg} \mathrm{L}^{-1}$ (0.46\% yield), with similar acetogenesis, cell growth, glycerol utilization, and porphyrin formation (Fig. 7). We then evaluated the effects of hemC repression in DMH-D9 $\Delta s d h A$ under microaerobic conditions and observed slightly better PBG biosynthesis, achieving a final PBG titer of $62.5 \mathrm{mg} \mathrm{L}^{-1}$ (0.53\% yield), with reduced porphyrin formation (Fig. 7). Note that the peak PBG titers for $\mathrm{DMH}$ and $\mathrm{DMH} \Delta s d h A$ cultivations were comparatively higher than that for DMH-D9 $\Delta s d h A$, implying PBG was rather unstable under such genetic backgrounds. Similar genetic and metabolic effects under microaerobic conditions described above in DMH single-mutant strains were also observed in the corresponding DSL single-mutant strains with higher hemB gene dosages. The final PBG titers for microaerobic bioreactor cultivation were $57.9,67.2$, and $83.8 \mathrm{mg} \mathrm{L}^{-1}$ for DSL, DSL $\Delta s d h A$, and DSL-D9 $\Delta s d h A$, respectively (Fig. 8). Note that the PBG yield for DSL-D9AsdhA was only 1.16-fold that for DSL $\Delta s d h A$, suggesting that the effect of hem $C$ repression on PBG biosynthesis and accumulation was insignificant under microaerobic conditions. 

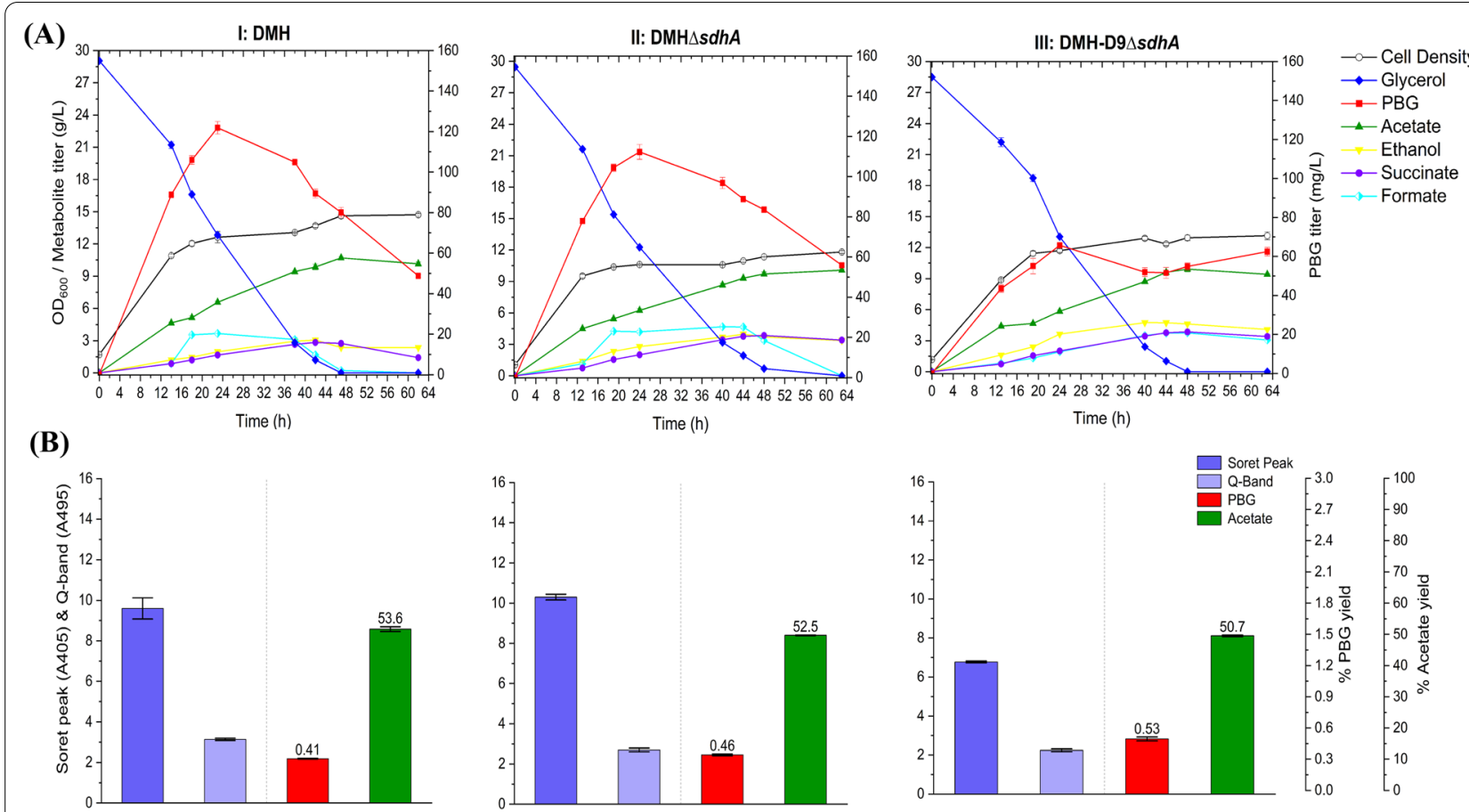

Fig. 7 Bioreactor cultivation of DMH, DMH $\Delta s d h A$, and DMH-D9 $\Delta s d h A$ for PBG biosynthesis under microaerobic conditions. Time profiles of cell density $\left(\mathrm{OD}_{600}\right)$, glycerol consumption and metabolite production profiles, acetate and PBG percentage yields, and extracellular accumulation of porphyrins (represented by the absorbance readings of the Soret peak (A405) and Q-band (A495)) are shown. The percentage yields of acetate/PBG and absorbance readings of porphyrin compounds are calculated/measured based on the consumed glycerol at end of cultivation. (I) $\mathrm{DMH}$, (II) $\mathrm{DMH} \Delta s d h A$, (III) DMH-D9 $\Delta s d h A$. All values are reported as means $\pm \mathrm{SD}(n=2)$

\section{Discussion}

As an intermediate in the metabolic pathway for essential porphyrin biosynthesis, PBG barely accumulates and, therefore, can be hardly detected in the extracellular medium upon cultivation of wild-type E. coli. In this study, we employed genetic and metabolic strategies for strain engineering of $E$. coli to enhance PBG biosynthesis for extracellular accumulation. First, the Shemin/C4 pathway was genetically implemented in $E$. coli by heterologous expression of hemA from R. sphaeroides to mediate molecular fusion of succinyl-CoA and glycine to form the key precursor 5-ALA for biosynthesis of PBG and porphyrins. Second, metabolic strategies were applied to direct carbon flux from the TCA pathways to the C4 pathway via the succinyl-CoA node. Third, the metabolic flux within the $\mathrm{C} 4$ pathway was further boosted by heterologous co-expression of hemA from $R$. spheroides and the native $E$. coli hemB. Finally, CRISPRi was applied to repress hemC expression to promote PBG accumulation with minimal impact to cell physiology and viability. PBG biosynthesis and accumulation in various engineered $E$. coli strains were characterized using bioreactor cultivation under different oxygenic (i.e., aerobic and microaerobic) conditions. Note that inclusion of episomal plasmids for heterologous expression of genes and implementing CRISPRi strategy in various engineered strains require constant use of antibiotic selection during cultivation, subsequently increasing the overall production cost.

Compared to the native E. coli in which porphyrin biosynthesis was primarily mediated via the C5 pathway, implementation of the heterologous $\mathrm{C} 4$ pathway significantly enhanced porphyrin biosynthesis based on visualization of high red-pigmentation upon bacterial cultivation (Additional file 1: Table S3). Nevertheless, PBG titer remained low with significant carbon spill toward acetogenesis, as shown in the control strain DMH cultivated under aerobic conditions. Since succinyl-CoA serves as a key precursor of the C4 pathway for biosynthesis of PBG and porphyrins, metabolic strategies were developed to increase this precursor supply. In E. coli, succinyl-CoA can be derived via three oxygen-dependent TCA pathways: (i) reductive TCA branch; (ii) oxidative TCA cycle, and (iii) glyoxylate shunt (Fig. 1) (Cheng et al. 2013). In this study, we explored two metabolic routes for carbon flux direction toward succinyl-CoA within the TCA pathways, i.e., (i) deregulated glyoxylate shunt and reductive TCA branch via the double mutation of $i c l R$ and $s d h A$ under aerobic conditions, and (ii) reductive 


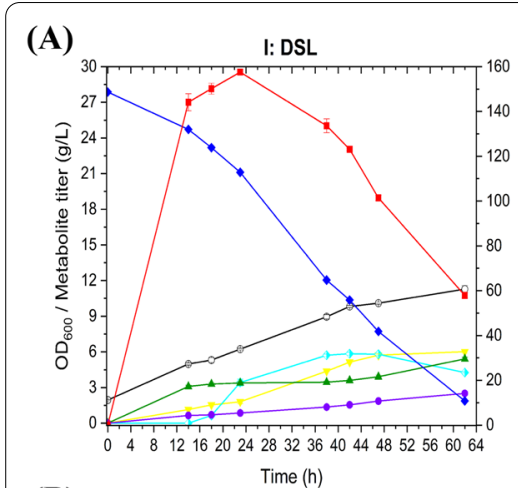

(B)
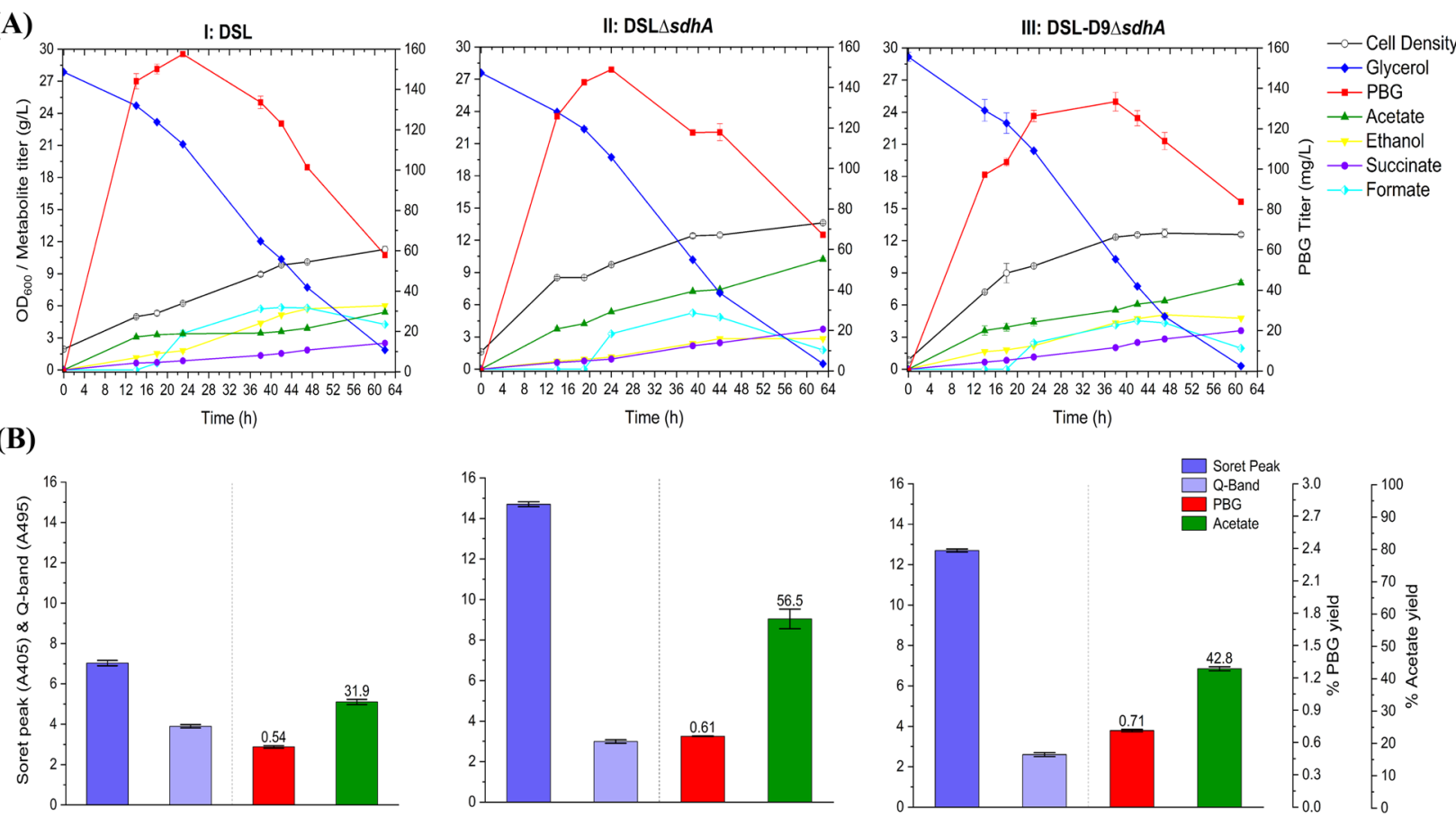

8 Bioreactor cultivation of DSL, DSL $\triangle s d h A$ and DSL-D9 $\triangle s d h A$ for PBG biosynthesis under microaerobic conditions. Time profiles of cell density $\left(\mathrm{OD}_{600}\right)$, glycerol consumption and metabolite production profiles, acetate and PBG percentage yields, and extracellular accumulation of porphyrins (represented by the absorbance readings of the Soret peak (A405) and Q-band (A495)) are shown. The percentage yields of acetate/PBG and absorbance readings of porphyrin compounds are calculated/measured based on the consumed glycerol at end of cultivation. Final PBG titer comparison for DSL, DSL $\triangle s d h A$, and DSL-D9 $\Delta s d h A$ was deemed to be statistically significant (Additional file 1: Table S4). (I) DSL, (II) DSL $\Delta s d h A$, (III) DSL-D9 $\Delta$ shhA. All values are reported as means $\pm \mathrm{SD}(n=2)$

TCA branch via the single mutation of $s d h A$ under microaerobic conditions. Hence, the effects of individual single mutations and double mutation of $i c l R$ and $s d h A$ on PBG biosynthesis were investigated.

Under aerobic conditions, biosynthesis of PBG and porphyrins was enhanced in DMH $\Delta i c l R \Delta s d h A$ compared to the control DMH, suggesting that carbon flux was successfully directed toward succinyl-CoA and then into the C4 pathway. Also, note that acetogenesis was reduced upon involving glyoxylate shunt (which can bypass decarboxylation associated with the oxidative TCA cycle) for carbon flux direction, improving biosynthesis yields for PBG and porphyrins. Nevertheless, a general trend of the time course of PBG titer remained unchanged, i.e., the PBG titer reached a peak value and then declined toward the end of the cultivation. Such PBG instability, potentially caused by unregulated subsequent reactions toward porphyrins, was alleviated by repression of hemC expression via CRISPRi in DMH-D9AiclRAsdhA. PBG (and porphyrin) biosynthesis was further enhanced by heterologous co-expression of hemA from $R$. spheroides and the native E. coli hemB and, most importantly, all the above metabolic and hemC-repression strategies were still functional under this new genetic background, as shown in all corresponding DSL strains. Note that ALA dehydratase (i.e., HemB, encoded by hemB) is subject to feedback inhibition by its downstream metabolite of protoporphyrinogen IX (PPIX) (Zhang et al. 2015), potentially limiting the PBG yield. Repression of hemC expression could potential reduce PPIX formation and its feedback inhibition on hemB expression, and subsequently increase PBG formation. The effects of heterologous expression of hemB could be clearly observed by much higher peak and final PBG titers between the corresponding DMH and DSL strains. The effects of amplification of various genes in the porphyrin biosynthetic pathway on porphyrin formation were documented (Lee et al. 2013). Note that, under aerobic culture conditions, the PBG yield of DSL-D9 $\Delta i c l R \Delta s d h A$ with all implemented metabolic and genetic strategies was 2.66 -fold that of the control DMH.

Under microaerobic conditions, succinyl-CoA was derived primarily via the reductive TCA branch (Shin et al. 2007) and, therefore, the oxidative TCA cycle had to be inactivated, such as mutating $s d h A$ in DMH $\Delta s d h A$, to support functional operation of the central metabolism. 
While PBG can be produced under microaerobic conditions, bioreactor cultivation suffered poor cell growth and glycerol utilization with significant acetogenesis and PBG instability. Interestingly, porphyrin biosynthesis appeared to be more effective under microaerobic conditions (as evidenced by higher absorbance values for Soret peak and Q-band) than aerobic cultivation though PBG biosynthesis showed the opposite. Compared to aerobic cultivation, significant amounts of formate were observed for PBG-producing strains cultivated under microaerobic conditions, presumably due to the induced activity of pyruvate formate lyase (PFL) under oxygenlimited conditions instead of pyruvate dehydrogenase $(\mathrm{PDH})$ which is mostly active in oxygen-rich environment (Durnin et al. 2009). Adverse effects arising from accumulated formate and acetate on culture performance were reported (Kirkpatrick et al. 2001). Nevertheless, the strain engineering strategies developed for aerobic cultivation, specifically heterologous hemB expression and repression of hemC expression, were still applicable to microaerobic cultivation though the improving effects were less significant than those under aerobic conditions. Under microaerobic culture conditions, the PBG yield of DSL-D9 $\Delta s d h A$ with all implemented strain engineering strategies was 1.73-fold that of the control DMH.

This study has several advantages over other reported PBG biosynthesis studies in variety of microbial systems. We utilized glycerol as cheap feedstock for direct PBG biosynthesis, compared to the process of PBG preparation from 5-ALA by pretreated cells of Chromatium vinosum (Vogelmann et al. 1975). We attained a PBG concentration of $0.182 \mathrm{mmol} / \mathrm{g}-\mathrm{DCW}$ in $E$. coli without extraneous supplementation of succinate and glycine. We obtained maximum PBG concentration of $924 \mu \mathrm{M}$ compared to $72 \mu \mathrm{M}$ from Propionibacterium freudenreichii (Piao et al. 2004) or $200 \mu \mathrm{M}$ from Rhodopseudomonas spheroids (Hatch and Lascelles 1972b).

\section{Conclusions}

In this study, we demonstrated that implementation of the non-native C4 pathway in E. coli was effective to supply carbon flux from the natural TCA pathways for PBG biosynthesis via succinyl-CoA. Metabolic engineering and bioprocessing strategies were further applied for effective carbon flux direction from the TCA pathways to the C4 pathway for enhanced PBG biosynthesis. To promote PBG accumulation, CRISPRi was successfully applied to repress hemC expression with minimal impact to cell physiology. The heterologous expression of the native E. coli hemB further enhanced overall PBG biosynthesis which was limited by fusion of two 5-ALA molecules catalyzed by HemB.
Overall, we enhanced PBG formation and accumulation in engineered $E$. coli by utilizing a cheap carbon source for direct biosynthesis without precursor supplementation. In addition, potential biochemical, genetic, and metabolic factors limiting PBG production were characterized.

\begin{abstract}
Abbreviations
5-ALA: 5-Aminolevulinic acid; CoA: Coenzyme A; CRISPRi: Clustered Regularly Interspersed Short Palindromic Repeats interference; DCW: Dry cell weight; $E$. coli: Escherichia coli; HemA: ALA synthase from Rhodopseudomonas spheroids (encoded by hemA); HemB: ALA dehydratase (encoded by hemB); HemC: Porphobilinogen deaminase (PBGD) (encoded by hemC); HMB: Hydroxymethylbilane; ICIR: Transcriptional AceBAK operon repressor (encoded by ic/R); PBG: Porphobilinogen; rpm: Revolutions per minute; SdhA: Succinate dehydrogenase (SDH) complex flavoprotein subunit A (encoded by sdhA); TCA :Tricarboxylic acid; vvm: Air volume/culture volume/min.
\end{abstract}

\section{Supplementary Information}

The online version contains supplementary material available at https://doi. org/10.1186/s40643-021-00482-3.

Additional file 1: Table S1. DNA oligonucleotide sequences used in this study. Table S2. gRNA sequences targeting hem C for CRISPRi in this study. See Additiona file 1: Figure S1 for qRT-PCR results for select gRNAs. Table S3. Tabulated images of bioreactor cultivation samples under aerobic and microaerobic conditions. Table S4. Statistical analysis for comparing experimental data of PBG titers. Figure S1. Quantification of the relative hem C expression for select gRNAs using qRT-PCR. All qRT-PCR values are reported as means \pm SD $(n=2)$. Figure S2. Bioreactor cultivation of DSL-D1 $\Delta i c / R \Delta s d h A$, DSL-D2 $\Delta i c / R \Delta s d h A, D S L-D 3 \Delta i c I R \Delta s d h A$, and DSL-D4 $\triangle i C / R \triangle s d h A$ for PBG biosynthesis under aerobic conditions. Time profiles of cell density $\left(O D_{600}\right)$, glycerol consumption and metabolite extracellular accumulation profiles are shown. (I) DSL-D1 $\Delta i c I R \Delta s d h A$,

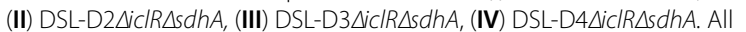
values are reported as means $\pm S D(n=2)$. Figure S3. Bioreactor cultivation of DSL-D5 $\Delta i c / R \Delta s d h A, D S L-D 6 \Delta i c I R \Delta s d h A, D S L-D 7 \Delta i c / R \Delta s d h A$, and DSL-D8 $\Delta i c / R \Delta s d h A$ for PBG biosynthesis under aerobic conditions. Time profiles of cell density $\left(\mathrm{OD}_{600}\right)$, glycerol consumption and metabolite extracellular accumulation profiles are shown. (I) DSL-D5 $\Delta i c I R \Delta s d h A$, (II)

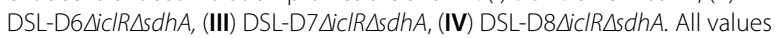
are reported as means $\pm \mathrm{SD}(n=2)$.

Acknowledgements

Not applicable.

\section{Authors' contributions}

DL and DM conceived the study. DL formulated research plan, coordinated research team, carried out experiments, performed result interpretation and data analysis, and drafted the manuscript. DM, MB, AW, and MA provided technical assistance on experimentation. MM-Y and CPC conceived, planned, supervised, and managed the study as well as helped to draft the manuscript. All authors read and approved the final manuscript.

\section{Funding}

This work was supported by the following Government of Canada grant: Natural Sciences and Engineering Research Council (NSERC) Discovery grant RGPIN-2019-04611.

Availability of data and materials

Most of data generated or analyzed during this study are included in this published article and its Additional file 1. Additional file 1 data can be made available from the corresponding author upon reasonable request. 


\section{Declarations}

Ethics approval and consent to participate

Not applicable.

\section{Consent for publication}

Not applicable.

\section{Competing interests}

The authors declare that they have no competing interests.

Received: 3 September 2021 Accepted: 4 December 2021

Published online: 13 December 2021

\section{References}

Anderson KE (2019) Acute hepatic porphyrias: Current diagnosis \& management. Mol Genet Metab 128(3):219-227. https://doi.org/10.1016/j. ymgme.2019.07.002

Baba T, Ara T, Hasegawa M, Takai Y, Okumura Y, Baba M, Mori H (2006) Construction of Escherichia coli K-12 in-frame, single-gene knockout mutants: the Keio collection. Mol Syst Biol. https://doi.org/10.1038/msb4100050

Chen X, Zhou L, Tian K, Kumar A, Singh S, Prior BA, Wang Z (2013) Metabolic engineering of Escherichia coli: a sustainable industrial platform for biobased chemical production. Biotechnol Adv 31(8):1200-1223. https://doi. org/10.1016/j.biotechadv.2013.02.009

Cheng K-K, Wang G-Y, Zeng J, Zhang J-A (2013) Improved succinate production by metabolic engineering. Biomed Res Int 2013:1-12. https://doi. org/10.1155/2013/538790

Cherepanov PP, Wackernagel W (1995) Gene disruption in Escherichia coli: TcR and KmR cassettes with the option of Flp-catalyzed excision of the antibiotic-resistance determinant. Gene 158(1):9-14. https://doi.org/10. 1016/0378-1119(95)00193-A

Ciriminna R, Pina CD, Rossi M, Pagliaro M (2014) Understanding the glycerol market. Eur J Lipid Sci Technol 116(10):1432-1439. https://doi.org/10. 1002/ejlt.201400229

Datsenko KA, Wanner BL (2000) One-step inactivation of chromosomal genes in Escherichia coli K-12 using PCR products. Proc Natl Acad Sci 97(12):6640-6645

Dharmadi Y, Murarka A, Gonzalez R (2006) Anaerobic fermentation of glycerol by Escherichia coli: a new platform for metabolic engineering. Biotechnol Bioeng 94(5):821-829. https://doi.org/10.1002/bit.21025

Durnin G, Clomburg J, Yeates Z, Alvarez PJ, Zygourakis K, Campbell P, Gonzalez $R$ (2009) Understanding and harnessing the microaerobic metabolism of glycerol in Escherichia coli. Biotechnol Bioeng 103(1):148-161. https:// doi.org/10.1002/bit.22246

Frankenberg N, Moser J, Jahn D (2003) Bacterial heme biosynthesis and its biotechnological application. Appl Microbiol Biotechnol 63(2):115-127. https://doi.org/10.1007/s00253-003-1432-2

Frydman B, Despuy ME, Rapoport H (1965) Pyrroles from Azaindoles. A synthesis of porphobilinogen. J Am Chem Soc 87:3530-3531. https://doi.org/10. 1021/ja01093a06

Frydman B, Reil S, Despuy ME, Rapoport H (1969) Pyrroles from azaindoles. A synthesis of porphobilinogen and related pyrroles. J Am Chem Soc 91(9):2338-2342. https://doi.org/10.1021/ja01037a025

Gibson SL, Mackenzie JC, Goldberg A (1968) The diagnosis of industrial lead poisoning. Br J Ind Med 25(1):40-51. https://doi.org/10.1136/oem.25.1.40

Hatch T, Lascelles J (1972a) Accumulation of porphobilinogen and other pyrroles by mutant and wild-type rhodopseudomonas-spheroides - regulation by heme. Arch Biochem Biophys 150(1):147. https://doi.org/10.1016/ 0003-9861(72)90021-5

Hatch T, Lascelles J (1972b) Accumulation of porphobilinogen and other pyrroles by mutant and wild type Rhodopseudomonas spheroides: regulation by heme. Arch Biochem Biophys 150(1):147-153. https://doi.org/10. 1016/0003-9861(72)90021-5

Jackson A, MacDonald S (1957) Synthesis of porphobilinogen. Can J Chem 35(7):715-722
Jacobi PA LiYK (2001) Synthesis of porphobilinogen via a novel ozonide cleavage reaction. J Am Chem Soc 123(38):9307-9312. https://doi.org/10. 1021/ja016303q

Jahn D, Verkamp E, Soll D (1992) Glutamyl-transfer RNA: a precursor of heme and chlorophyll biosynthesis. Trends Biochem Sci 17(6):215-218. https:// doi.org/10.1016/0968-0004(92)90380-r

Jobling MG, Holmes RK (1990) Construction of vectors with the p15a replicon, kanamycin resistance, inducible lacZ alpha and pUC18 or pUC19 multiple cloning sites. Nucleic Acids Res 18(17):5315-5316. https://doi.org/10. 1093/nar/18.17.5315

Jones MI, Froussios C, Evans DA (1976) A short, versatile synthesis of porphobilinogen. J Chem Soc Chem Commun. https://doi.org/10.1039/C3976 0000472

Kenner GW, Rimmer J, Smith KM, Unsworth JF (1977) Pyrroles and related compounds. Part 38. Porphobilinogen synthesis. J Chem Soc Perkin 1(3):332-340

Kirkpatrick C, Maurer LM, Oyelakin NE, Yoncheva YN, Maurer R, Slonczewski JL (2001) Acetate and formate stress: opposite responses in the proteome of Escherichia coli. J Bacteriol 183(21):6466-6477. https://doi.org/10.1128/JB. 183.21.6466-6477.2001

Labun K, Montague TG, Gagnon JA, Thyme SB, Valen E (2016) CHOPCHOP v2: a web tool for the next generation of CRISPR genome engineering. Nucleic Acids Res 44(W1):W272-W276

Layer G, Reichelt J, Jahn D, Heinz DW (2010) Structure and function of enzymes in heme biosynthesis. Protein Sci 19(6):1137-1161. https://doi. org/10.1002/pro.405

Lee MJ, Kim HJ, Lee JY, Kwon AS, Jun SY, Kang SH, Kim P (2013) Effect of gene amplifications in porphyrin pathway on heme biosynthesis in a recombinant Escherichia coli. J Microbiol Biotechnol 23(5):668-673. https://doi. org/10.4014/jmb.1302.02022

Leung GC, Fung SS, Gallio AE, Blore R, Alibhai D, Raven EL, Hudson AJ (2021) Unravelling the mechanisms controlling heme supply and demand. Proc Natl Acad Sci U S A. https://doi.org/10.1073/pnas.2104008118

Mauzerall D, Granick S (1956) THE occurrence and determination of $\delta$-aminolevulinic acid and porphobilinogen in urine. J Biol Chem 219(1):435-446

Miller JH (1992) A short course in bacterial genetics: a laboratory manual and handbook for Escherichia coli and related bacteria. Cold Spring Harbor Laboratory Press, NY

Miscevic D, Mao JY, Kefale T, Abedi D, Moo-Young M, Perry Chou C (2021) Strain engineering for high-level 5-aminolevulinic acid production in Escherichia coli. Biotechnol Bioeng 118(1):30-42. https://doi.org/10.1002/ bit.27547

Möbius K, Arias-Cartin R, Breckau D, Hännig AL, Riedmann K, Biedendieck R, Schröder S, Becher D, Magalon A, Moser J, Jahn M (2010) Heme biosynthesis is coupled to electron transport chains for energy generation. Proc Natl Acad Sci 107(23):10436-10441

Nandi DL (1978) Delta-aminolevulinic acid synthase of Rhodopseudomonas spheroids. Binding of pyridoxal phosphate to the enzyme. Arch Biochem Biophys 188(2):266-271. https://doi.org/10.1016/s0003-9861(78)80008-3

Neidhardt FC, Bloch PL, Smith DF (1974) Culture medium for enterobacteria. J Bacteriol 119(3):736-747

Neier R (2000) A novel synthesis of porphobilinogen: Synthetic and biosynthetic studies. J Heterocycl Chem 37:487-508

Pengpumkiat S, Koesdjojo M, Rowley ER, Mockler TC, Remcho VT (2016) Rapid synthesis of a long double-stranded oligonucleotide from a singlestranded nucleotide using magnetic beads and an Oligo library. PLoS ONE 11(3):e0149774-e0149774. https://doi.org/10.1371/journal.pone. 0149774

Piao Y, Kiatpapan P, Yamashita M, Murooka Y (2004) Effects of expression of hem $A$ and hemB genes on production of porphyrin in Propionibacterium freudenreichii. Appl Environ Microbiol 70(12):7561-7566. https://doi.org/ 10.1128/AEM.70.12.7561-7566.2004

Qi LS, Larson MH, Gilbert LA, Doudna JA, Weissman JS, Arkin AP, Lim WA (2013) Repurposing CRISPR as an RNA-guided platform for sequence-specific control of gene expression. Cell 152(5):1173-1183. https://doi.org/10. 1016/j.cell.2013.02.022

Shin J-A, Kwon YD, Kwon OR, Lee ES, Kim P (2007) 5-aminolevulinic acid biosynthesis in Escherichia coli coexpressing NADP-dependent malic enzyme and 5-aminolevulinate synthase. J Microbiol Biotechnol 17(9):1579-1584 
Srirangan K, Liu X, Westbrook A, Akawi L, Pyne ME, Moo-Young M, Chou CP (2014) Biochemical, genetic, and metabolic engineering strategies to enhance coproduction of 1-propanol and ethanol in engineered Escherichia coli. Appl Microbiol Biotechnol 98(22):9499-9515. https://doi.org/10. 1007/s00253-014-6093-9

Thakker C, Martinez I, San KY, Bennett GN (2012) Succinate production in Escherichia coli. Biotechnol J 7(2):213-224. https://doi.org/10.1002/biot. 201100061

Vogelmann H, Ghahremani B, Wagner F (1975) Preparation of porphobilinogen and uroporphyrin III from $\delta$-aminolaevulinic acid by pretreated cells of Chromatium vinosum. Eur J Appl Microbiol Biotechnol 2(1):19-28

Westall RG (1952) Isolation of porphobilinogen from the urine of a patient with acute porphyria. Nature 170(4328):614-616. https://doi.org/10.1038/ $170614 a 0$

Westbrook AW, Miscevic D, Kilpatrick S, Bruder MR, Moo-Young M, Chou CP (2019) Strain engineering for microbial production of value-added chemicals and fuels from glycerol. Biotechnol Adv 37(4):538-568. https:// doi.org/10.1016/j.biotechadv.2018.10.006

Zhang J, Kang Z, Chen J, Du G (2015) Optimization of the heme biosynthesis pathway for the production of 5-aminolevulinic acid in Escherichia coli. Sci Rep 5:8584. https://doi.org/10.1038/srep08584

\section{Publisher's Note}

Springer Nature remains neutral with regard to jurisdictional claims in published maps and institutional affiliations.

\section{Submit your manuscript to a SpringerOpen ${ }^{\odot}$ journal and benefit from:}

- Convenient online submission

- Rigorous peer review

- Open access: articles freely available online

- High visibility within the field

Retaining the copyright to your article

Submit your next manuscript at $\boldsymbol{\nabla}$ springeropen.com 